UNIVERSIDADE DE BRASÍLIA

FACULDADE DE EDUCAÇÃO FÍSICA

\title{
INTERAÇÃO ENTRE BARORRECEPTORES CARDIOPULMONARES E REFLEXO PRESSOR DO \\ EXERCÍCIO NO CONTROLE AUTÔNOMICO DA FREQUÊNCIA CARDÍACA EM HUMANOS
}

MAYARA CAROLINE DA COSTA SOUZA

BRASÍLIA 
INTERAÇÃO ENTRE BARORRECEPTORES CARDIOPULMONARES E REFLEXO PRESSOR DO EXERCÍCIO NO CONTROLE AUTÔNOMICO DA FREQUÊNCIA CARDÍACA EM HUMANOS

MAYARA CAROLINE DA COSTA SOUZA

Dissertação apresentada à Faculdade de Educação Física da Universidade de Brasília, como requisito parcial para obtenção do grau de Mestre em Educação Física.

ORIENTADOR: PROF. Dr. LAURO CASQUEIRO VIANNA 
MAYARA CAROLINE DA COSTA SOUZA

INTERAÇÃO ENTRE BARORRECEPTORES CARDIOPULMONARES E REFLEXO PRESSOR DO EXERCÍCIO NO CONTROLE AUTÔNOMICO DA FREQUÊNCIA CARDÍACA EM HUMANOS

Dissertação apresentada à Faculdade de Educação Física da Universidade de Brasília, como requisito parcial para obtenção do grau de Mestre em Educação Física.

Brasília, 14 de setembro de 2016.

BANCA EXAMINADORA

Prof. Dr. Lauro Casqueiro Vianna

(Presidente- PPGEF/UnB)

Prof. Dr. Plínio dos Santos Ramos

(Membro externo- SUPREMA)

Dr. Mauricio Daher Andrade Gomes

(Membro externo- ICDF) 
Ficha catalográfica elaborada automaticamente, com os dados fornecidos pelo(a) autor(a)

Souza, Mayara Caroline da Costa

INTERAÇÃO ENTRE BARORRECEPTORES CARDIOPULMONARES

E REFLEXO PRESSOR DO EXERCÍCIO NO CONTROLE AUTÔNOMICO

DA FREQUÊNCIA CARDÍACA EM HUMANOS / Mayara Caroline

da Costa Souza; orientador Lauro Casqueiro Vianna. Brasilia, 2016. $56 \mathrm{p}$.

Dissertação (Mestrado - Mestrado em Educação Física) -- Universidade de Brasília, 2016.

1. Mecanismos de regulação sistema cardíaco. 2 . Frequência cardíaca. 3. Metaborreflexo muscular. 4. Barorreceptores cardiopulmonares. I. Vianna, Lauro Casqueiro, orient. II. Título. 


\section{AGRADECIMENTOS}

Uma das "duras" missões dos seres humanos é o reconhecimento adequado a vida pelas oportunidades que the são dadas. Mas me dou aqui mais esta missão de agradecer a todos que passaram por minha vida até o momento e deixaram comigo um pouquinho de si.

Agradeço minha mãe que esteve sempre comigo, dando amor e força. Obrigada por acreditar em mim e apoiar todas as minhas decisões por mais inseguras e arriscadas que fossem. Agradeço minhas irmãs, Leticia Costa e Jessica Costa, pelo apoio. Mesmo que talvez não saibam, vocês me motivam a acordar toda manhã e persistir neste caminho com determinação.

Ao meu orientador prof. Dr. Lauro Vianna, que apostou e acreditou no meu trabalho nesse curto espaço de tempo e que me proporcionou imensurável conhecimento. Pelo excepcional exemplo de profissional e ser humanos que é. Obrigada pelos ensinamentos de vida e pelos "Happy hours" históricos.

Agradeço aos amigos do NeuroVASQ, que com certeza merecem ser citados um a um pela importância que tiveram diariamente. Ao camisa $10 \mathrm{Me}$. André Teixeira, pelas broncas, pela paciência em ensinar, por sempre estar disposto a me ajudar e me aturar por todo esse tempo, um irmão mais velho que levarei comigo; ao Nino, Diego Antonino, nosso salvador de gatinhos que por tantas vezes foi o equilíbrio entre a "loucura" e o bom senso no grupo, "coração de menino que pega ar a depender da situação" e ao Tchelo (Paulo Marcelo), pelos vários "puxões" de orelha e pelos "abraçinhos" da paz que tantas vezes "me acalmaram". "Meninos obrigada por me 
fazerem aprender diariamente um pouquinho mais sobre o obscuro universo masculino e suas peculiaridades :.

Ainda aos integrantes do NeuroVASQ, apesar do pouco tempo e do rápido convívio, agradeço ao pós doutorando Plinio Ramos, pelas orientações no estudo e pelos ensinamentos. Agradeço à nova "girl" do laboratório, Ma. Milena Samora, que me socorreu por vezes e é a parceira que me faltava. "Mi estou te passando a coroa, toma conta dos meninos e não deixe que eles te enlouqueçam". Ao menino de bigode, Me. Jeann Sabino, que chegou agregando ao laboratório com seu entusiasmo. A todos integrantes e agregados do NeuroVASQ, que de uma forma ou de outra me proporcionaram novos aprendizados.

Agradeço aos meus amigos que permaneceram presentes, mesmo com minha ausência. À minha melhor, Vanessa Rodrigues, que tanto me apoio e se orgulhou a cada nova conquista; à minha "BFF", Lara Silveira, que diariamente segurou na minha mão e me fez sentir capaz, dando força para não desistir por mais que os obstáculos fossem grandes. Ao amigo e parceiro Fabrício Galdino que por vezes me socorreu nos meus desesperos e me dava aquele "puxão" para vida que só melhores amigos sabem dar. Ao meu grande amigo Ademar Azevedo, que apesar da vida tumultuada sempre dava um jeito de estar comigo nos momentos em que mais precisava e confortava meu coração com suas palavras.

Aos voluntários que participaram desse estudo, sem vocês nada disso seria possível. Por fim, agradeço a todos que direta ou indiretamente contribuíram para a realização de mais esse sonho. 
SUMÁRIO

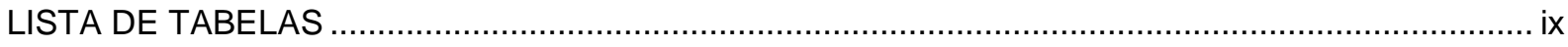

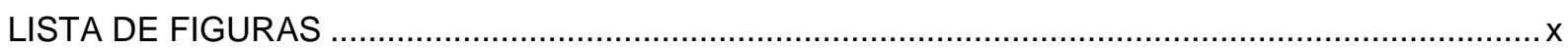

LISTA DE SIGLAS, ABREVIAÇÕES E SÍMBOLOS …….......................................................

RESUMO

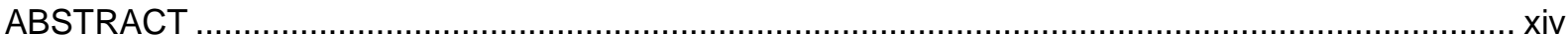

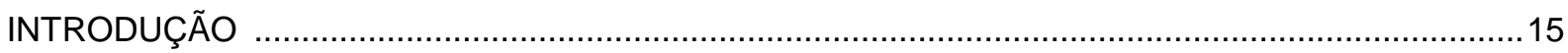

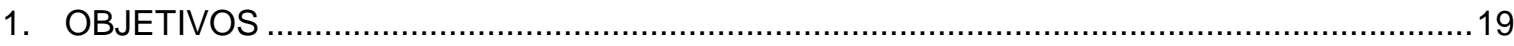

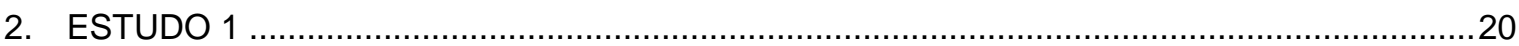

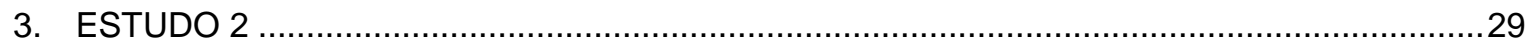

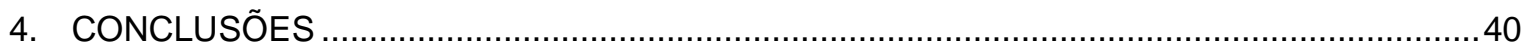

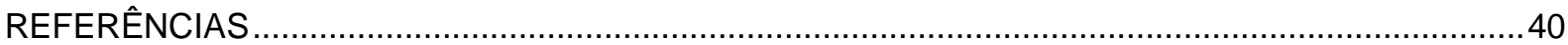

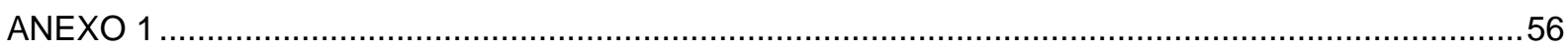




\section{LISTA DE TABELAS}

TABELA 1 - EXERCÍCIO DE PREENSÃO MANUAL ….......................................... 18

TABELA 2 - EXERCÍCIO DE MEMBROS INFERIORES …...................................19

TABELA 3 - CARACTERIZAÇÃO DA AMOSTRA ..............................................26

TABELA 4 - VARIÁVEIS CARDIOVASCULARES EM REPOUSO ….......................27 


\section{LISTA DE FIGURAS}

FIGURA 1 - FLUXOGRAMA SISTEMATIZADO DA BUSCA DOS ARTIGOS ..........17

FIGURA 2 - PROCEDIMENTOS EXPERIMENTAIS ..................................... 26

FIGURA 3 - RESULTADOS VARIÁVEIS HEMODINÂMICAS ......................... 27

FIGURA 4 - RESULTADOS VARIÁVEIS HEMODINÂMICAS COM BLOQUEIO...... 28

FIGURA 5 - ESQUEMA DEMONSTRANDO AS AFERÊNCIAS ......................... 30 


\section{LISTA DE SIGLAS, ABREVIAÇÕES E SÍMBOLOS}

\begin{tabular}{|c|c|}
\hline BPM & Batimentos Por Minuto \\
\hline CM & Centímetros \\
\hline CNS & Conselho Nacional de Saúde \\
\hline CVM & Contração Voluntária Máxima \\
\hline DC & Débito Cardíaco \\
\hline DP & Desvio Padrão \\
\hline FC & Frequência Cardíaca \\
\hline IMC & Índice de Massa Corporal \\
\hline $\mathrm{Kg}$ & Kilograma \\
\hline $\mathrm{mmHg}$ & Milímetro de Mercúrio \\
\hline Min & Minuto \\
\hline$M g$ & Miligrama \\
\hline MEDLINE & National Library of Medicine \\
\hline OCPE & Oclusão Circulatória pós Exercício \\
\hline PA & Pressão Arterial \\
\hline PAD & Pressão Arterial Diastólica \\
\hline PAM & Pressão Arterial Média \\
\hline PAS & Pressão Arterial Sistólica \\
\hline PSE & Percepção Subjetiva de Esforço \\
\hline RPE & Reflexo Pressor do Exercício \\
\hline RPT & Resistência Periférica Total \\
\hline RPM & Rotações por Minuto \\
\hline Seg & Segundo \\
\hline VS & Volume Sistólico \\
\hline Vs & Verso \\
\hline
\end{tabular}




\section{RESUMO}

Nos seres humanos, a ativação isolada do metaborreflexo muscular por meio de oclusão circulatória pós exercício (OCPE) tem um efeito importante no aumento da atividade nervosa simpática. Isto pode causar vasoconstrição periférica e manter parcialmente o aumento da pressão arterial (PA) induzido pelo exercício. Á atuação do metaborreflexo na frequência cardíaca (FC) não está bem elucidada na literatura, diante disso uma revisão sistemática foi realizada, com objetivo de verificar o impacto da ativação metaborreflexo muscular na regulação da FC em humanos. Para isso, buscas no PubMED foram realizadas utilizando palavras chaves especificas para selecionar artigos que contemplassem o tema estudado, também foram escolhidos artigos sugeridos por pesquisadores experts na área para deixar a pesquisa mais robusta e completa. Após finalização das buscas e encaixe nos critérios de inclusão e exclusão, 75 estudos foram incluídos. Apenas $2 \%$ dos estudos analisados encontraram diferenças na regulação da FC mediante ativação do metaborreflexo muscular, enquanto 98\% dos estudos concluíram não haver diferença nessa variável. Sabe-se que, uma menor resposta na frequência cardíaca (FC) pode ser evocada através do bloqueio farmacológico do receptor $\beta-1$ adrenérgico. Uma carga dos receptores cardiopulmonares, associado a posição supina, também fornece sinais neuromoduladores ao tronco cerebral o que pode provocar inibição simpática cardíaca. Diante disso, um estudo original foi realizado visando testar a hipótese de que a resposta simpática da FC mediada pela ativação do metaborreflexo muscular é anulada pela carga dos receptores cardiopulmonares em humanos. Dezenove homens saudáveis participaram do estudo (20 \pm 2 anos). A PA e a FC foram 
mensuradas continuamente, batimento a batimento, por um aparelho de fotopletismografia (ML 282B1-X, Adlnstruments). Após um período de repouso, foi realizado 90 segundos de exercício estático de preensão manual a 40\% da contração voluntária máxima seguida por três minutos de OCPE. Os protocolos foram realizados com (postura supina) ou sem (postura sentada) uma carga simultânea dos receptores cardiopulmonares. Em um subgrupo de 5 sujeitos foram repetidos os protocolos com bloqueio dos receptores $\beta$ adrenérgicos (Atenolol, $25 \mathrm{mg}$ ). Em repouso, a mudança da postura supina para postura sentada promoveu aumento da FC de $64 \pm 2$ para $69 \pm 2$ bpm $(P<0,05)$, enquanto a PAS diminuiu de $90 \pm 2$ para $84 \pm 2 \mathrm{mmHg}(P<0,05) . A$ OCPE provocou um aumento robusto da PAM de repouso $(\Delta 36 \pm 3 \mathrm{mmHg}, \mathrm{P}<0,05)$, que não foi afetada pela postura corporal. Durante a OCPE na postura sentada, a FC aumentou em relação ao repouso ( $\Delta 10 \pm 2 \mathrm{bpm}, \mathrm{P}>0,05$ vs. repouso) porém foi atenuada com a carga dos receptores cardiopulmonares ( $\Delta 2 \pm 2$ bpm, $P>0,05$ vs. repouso). Após o bloqueio $\beta-1$ adrenérgico, a resposta da FC durante a OCPE na postura sentada foi reduzida ( $\Delta 5 \pm 3 \mathrm{bpm}, \mathrm{P}<0,05)$, enquanto que na posição supina a resposta da $\mathrm{FC}$ durante a OCPE não foi afetada $(\Delta 3 \pm 2 \mathrm{bpm}, \mathrm{P}>0,05)$. Em resumo, 0 presente estudo demonstra que na revisão de literatura realizada não se tem um consenso sobre o efeito da ativação do metaborreflexo muscular na regulação da FC, já no estudo original é possível concluir que, resposta da FC durante a ativação isolada do metaborreflexo muscular é aumentada pela inibição dos barorreceptores cardiopulmonares devido a um mecanismo $\beta$-1 adrenérgico.

Palavras-chave: Metaborreflexo muscular, Barorreceptores Cardiopulmonares; Frequência Cardíaca. 


\section{ABSTRACT}

In humans, activation of isolated muscle metaboreflex by circulatory occlusion post exercise (OCPE) has an important effect in increasing sympathetic nervous activity. This can cause peripheral vasoconstriction and partly to keep the increase in blood pressure (BP) induced by exercise. Á performance of metaboreflex in heart rate (HR) is not well elucidated in the literature on this systematic review was conducted, in order to verify the impact of metaboreflex muscle activation in $\mathrm{HR}$ regulation in humans. To do this, search the PubMED were performed using specific keywords to select articles that addressed the subject studied, were also selected articles suggested by experts researchers in the field to make the most robust and complete research. After completion of the search and fit the inclusion and exclusion criteria, 75 studies were included. Only $2 \%$ of the analyzed studies have found differences in HR regulation by activation of muscle metaboreflex, while $98 \%$ of the studies found no difference in this variable. It is known that a minor response in heart rate $(\mathrm{HR})$ can be raised through pharmacological blockade of $\beta-1$ adrenergic receptor. A load of cardiopulmonary receptors associated with supine position, neuromodulators also provides signals to the brainstem which may cause cardiac sympathetic inhibition. Thus, an original study was conducted to test the hypothesis that the friendly HR response mediated muscle metaboreflex activation is canceled by the load of cardiopulmonary receptors in humans. Nineteen healthy men participated in the study (20 \pm 2 years). BP and HR were measured continuously, beat to beat, by a PPG player (ML-282B1 X, ADInstruments). After a rest period, it was performed 90 seconds of static handgrip exercise at $40 \%$ of maximal voluntary contraction followed by three minutes of OCPE. 
The protocols were performed with (supine posture) or without (sitting position) simultaneous loading of cardiopulmonary receptors. In a subgroup of 5 subjects were repeated with lock protocols of $\beta$-adrenergic receptors (Atenolol $25 \mathrm{mg}$ ). At rest, change the supine posture to the sitting posture promoted increased HR $64 \pm 2$ to $69 \pm 2$ bpm $(P<0.05)$, while SBP decreased from $90 \pm 2$ to $84 \pm 2 \mathrm{~mm} \mathrm{Hg}(P<0,05)$. The OCPE caused a robust increase in the rest of $\operatorname{PAM}(\Delta 36 \pm 3 \mathrm{mmHg}, \mathrm{P}<0.05)$, which was not affected by body posture. During OCPE in the seated position, the HR increased in relation to rest $(\Delta 10 \pm 2 \mathrm{bpm}, \mathrm{P}>0.05 \mathrm{vs}$. rest) but was attenuated with the load of cardiopulmonary receptors ( $\Delta 2 \pm 2 \mathrm{bpm}, \mathrm{P}>0.05$ vs . rest). After $1 \beta$-adrenergic blockade, the HR response during OCPE was reduced in seated position ( $\Delta 5 \pm 3 \mathrm{bpm}$, $P<0.05)$, while in the supine position during the HR response was not affected OCPE $(\Delta 3 \pm 2 \mathrm{bpm}, \mathrm{P}>0.05)$. In summary, this study demonstrates that the literature review carried out there is no consensus on the muscle metaboreflex activation effect on HR regulation, as in the original study it can be concluded that HR response during the isolated activation of muscle metaboreflex it is increased by inhibition of cardiopulmonary baroreceptors due to a $\beta-1$ adrenergic mechanism.

Keywords: metaboreflex, baroreflex cardiopulmonary; heart rate. 


\section{INTRODUÇÃO}

Os ajustes cardiovasculares e hemodinâmicos em repouso e durante situações de estresse, como o exercício físico, são mediados por alterações no sistema nervoso autônomo por meio de estímulos excitatórios e inibitórios (Williamson, et al. 2006; Smith, et al. 2006; Kaufman e Hayes, 2002; Mitchell, et al. 1983). Esses ajustes são provenientes da interação de mecanismos neurais, sendo eles: Comando Central (Williamson, et al. 2006); Barorreflexo Arterial (Williamson, et al. 2006); Reflexo Pressor do Exercício (RPE) (Kaufman e Hayes, 2002; Mitchell, et al. 1983) e o Barorreceptores Cardiopulmonares. O comando central é responsável pelas alterações ocorridas no sistema cardiovascular imediatamente ao início do exercício, como o aumento da frequência cardíaca $(\mathrm{FC})$ que ocorre nos primeiros segundos decorrente da redução da ação vagal (Krogh e Lindhard, 1913; Mitchell, et al. 1989).

O barorreflexo arterial consiste em um sinal inibitório simpático responsável pelo ajuste da pressão arterial (PA) durante estímulo químico e/ou mecânico. Essa regulação é feita por meio de alterações na FC e no volume sistólico (VS), possibilitando assim o controle dos níveis pressóricos em diversas situações (Fisher, et al. 2015). O barorreflexo arterial age através de barorreceptores tonicamente ativos, localizados nas artérias carótida e aorta (Drew, et al. 2008; Smith, et al. 2005; Gallagher, et al. 2001; Kim, et al. 2011; Fadel, et al. 2003; Fadel, et al. 2003).

O RPE consiste na deteç̧ão de estímulos metabólicos (metaborreflexo) e mecânicos (mecanorreflexo) durante o exercício, que enviam aferências para áreas do sistema nervoso central, mais especificamente para o Núcleo do trato solitário, responsáveis pelo controle cardiovascular (Smith, et al. 2006). As fibras musculares do tipo III e IV correspondem ao mecanorreflexo (Vianna, 2010; Vianna, et al. 2009) e metaborreflexo respectivamente; 
(Mitchell, et al. 1983; Murphy, et al. 2012; Smith, et al. 2006; Alam e Smirk, 1937; Drew, et al. 2008), embora haja certo grau de polimodalidade das aferências e respostas a ambos os estímulos (Drew, et al. 2008; Fisher, et al. 2005).

O reflexo cardiopulmonar foi descoberto há mais de um século por Von Bezold e Jarish (1867), por meio de experimentos animais. Eles observaram a existência da interação entre os barorreceptores arteriais e fibras nervosas espalhadas pelo coração. Propondo que, os barorreceptores cardiopulmonares são estimulados por meio de mudanças de pressão nas câmeras cardíacas, localizado nos átrios, ventrículos e vasos pulmonares, esses receptores são conectados ao sistema nervoso central (SNC) e a medula espinhal. Além de possuir vasta localização, os sinais desses barorreceptores são distribuídos por diferentes fibras aferentes, vagais ou simpáticas, tendo a aferências vagal com maior predominância nas respostas desse mecanismo (Thoren, 1979; Coleridge et al., 1964).

A interação destes mecanismos modula a atividade do sistema nervoso autônomo produzindo mudanças na FC, VS, resistência periférica total (RPT) e consequentemente, na PA permitindo um aporte ótimo de oxigênio para os músculos esqueléticos ativos (Fisher, et al. 2015). Embora estes mecanismos sejam importantes para a regulação cardiovascular, maior atenção tem sido dada ao RPE, devido ao seu papel determinante na magnitude da simpatoexcitação durante o exercício (Smith, et al. 2006; Delaney, et al. 2010).

Em humanos, a ativação do metaborreflexo muscular pode ser estudada de maneira isolada por meio da oclusão circulatória pós-exercício (OCPE) do membro ativo (Smith, et al. 2006; Vianna, et al. 2009; Fisher, et al. 2005; Rondon, et al. 2006; Negrão, et al. 2001; Fadel, et al. 2003), o que permite diferenciar seus efeitos daqueles observados durante a realização do exercício voluntário em que ocorre a ativação conjunta do comando central e o RPE 
(metaborreflexo e mecanorreflexo muscular). Durante esta manobra, subprodutos metabólicos da contração muscular são mantidos no músculo esquelético (Koba, et al. 2008; Kaufman e Hayes, 2002) e estimulam as fibras aferentes tipo IV (i.e., metabolicamente sensíveis) (Kaufman e Hayes, 2002). Como resultado, são observados aumentos na PA atribuídos, principalmente, à vasoconstrição sistêmica mediada pela ativação simpática (SMITH, et al. 2006; Alam e Smirk, 1937; Rondon, et al. 2006; Fadel, et al. 2003).

Estudos apontam uma real influência do metaborreflexo muscular no aumento de PA durante o exercício (Baum et al., 1995; Fisher et al. 2010), no entanto, a resposta da FC mediada pela ativação isolada do metaborreflexo muscular ainda é contraditória (Notarrius et al. 2001; Fisher et al. 2010). A ativação do metaborreflexo muscular é conhecida por gerar informações que aumentam a atividade nervosa simpática, no entanto, não se tem um consenso sobre a influência da ativação metaboreflexa sobre o controle da FC. Diversos estudos demonstram não haver interação entre metaborreflexo e FC (lellamo, et al. 1999; Houssiere, et al. 2006; Kamiya, et al. 2011; Lykidis, et al. 2013; Holwerda, et al.2015), enquanto outros apontam haver uma influência do metaborreflexo sobre a FC em situação específicas, tendo observado um aumento de FC durante o metaborreflexo em exercícios de maior intensidade (Fisher et al. 2010; Freud, et al., 1978). Dessa forma, ainda não está claro na literatura a influência da ativação isolada do metaborreflexo muscular na resposta da FC em seres humanos.

Para responder a lacuna científica apresentada no parágrafo anterior, essa dissertação foi estruturada em dois artigos, sendo o primeiro uma revisão sistemática da literatura, que teve como objetivo determinar o impacto da ativação do metaborreflexo muscular na regulação da FC em humanos. E o segundo artigo, foi elaborado de modo a testar a hipótese de 
existência de uma interação do metaborreflexo muscular e os barorreceptores cardiopulmonares no controle autonômico da FC.

\section{OBJETIVOS}

\subsection{Objetivo geral}

Investigar o impacto da interação entre reflexos cardiopulmonar e pressor do exercício em variáveis hemodinâmicas.

\subsection{Objetivos específicos}

a) Determinar por meio de uma revisão sistemática, o impacto da ativação metaborreflexo muscular na regulação da FC em humanos (estudo 1).

b) Testar a hipótese de que a resposta simpática da FC mediada pela ativação do metaborreflexo muscular é anulada pela ativação dos barorreceptores cardiopulmonares em homens (estudo 2).

c) Testar a hipótese de que a regulação da FC durante ativação dos barorreceptores cardiopulmonares em conjunto com ativação do metaborreflexo isolado, ocorre devido a mecanismo $\beta-1$ adrenérgico (estudo 2). 


\section{ESTUDO 1}

Artigo de revisão

IMPACTO DA ATIVAÇÃO DO METABORREFLEXO MUSCULAR SOBRE A RESPOSTA DA FREQUÊNCIA CARDÍACA EM HUMANOS: UMA REVISÃO SISTEMÁTICA

Mayara C. Souza ${ }^{1}$ 


\author{
Plinio S. Ramos ${ }^{1,2}$ \\ André L. Teixeira ${ }^{1}$ \\ Diego Antonino ${ }^{1}$ \\ Paulo M. Maia- Lopes ${ }^{1}$ \\ Lauro C. Vianna ${ }^{1}$
}

1 - Faculdade de Educação Física, Universidade de Brasília (UnB), Brasília, DF, Brasil. 2 - Hospital e maternidade Therezinha de Jesus, Faculdade de Ciências Médicas e da Saúde (SUPREMA), Juiz de Fora, MG, Brasil.

\title{
Correspondente:
}

Dr. Lauro C. Vianna, Laboratório de Fisiologia integrativa - NeuroVASQ

Faculdade de Educação Física

Universidade de Brasília

Campus Darcy Ribeiro, Brasília, Brasil

tel.: +55 (61) 31072531

Fax: +55 (61) 31072512

E-mail: Icvianna@unb.br

\section{OBJETIVO}

O objetivo deste estudo foi determinar por meio de uma revisão sistemática, o impacto da ativação metaborreflexo muscular na regulação da FC em humanos.

\section{MÉTODOS}

\section{Estratégia de pesquisa}


Foram analisados os estudos mais relevantes publicados em Inglês, usando o banco de dados National Library of Medicine (MEDLINE), através do PubMed. Como estratégia de pesquisa foi utilizada a seguinte frase em inglês: (metaboreflex OR "muscle ischemia" OR "post exercise ischemia" OR "muscle ischemia" OR posthandgrip) AND ("heart rate" OR "RR interval").

A seleção dos artigos foi realizada com a participação de três pesquisadores respeitando quatro etapas. Na primeira, foi aplicado os filtros disponíveis na base PubMed, no qual foram excluídos os estudos realizados em modelos animais, estudos experimentais nãoclínicos, revisões e aqueles que não foram escritos em Inglês. A segunda etapa foi realizada através da leitura dos títulos e excluindo aqueles que não se encaixavam nos critérios de inclusão. A terceira etapa de exclusão foi realizada a leitura dos resumos dos estudos selecionados. Finalmente, todos os estudos não excluídos nas etapas anteriores foram lidos integralmente para a seleção de quais seriam incluídos nesta revisão. Após análise dos artigos pela busca digital na base de dados do PubMed, foram feitas buscas por meio do nome dos autores com publicações importantes (de grande relevância no tema e com descobertas significativas no assunto) sobre o tema e que tiveram artigos incluídas a partir da frase de pesquisa utilizada.

Os critérios de inclusão e exclusão foram aplicados livremente e de forma independente por três revisores com experiência anterior no assunto. Se qualquer divergência na análise dos manuscritos ocorreu, foi resolvido em uma reunião de consenso. A figura 1 demonstra 0 fluxograma da pesquisa dos artigos envolvidos nesse estudo. 


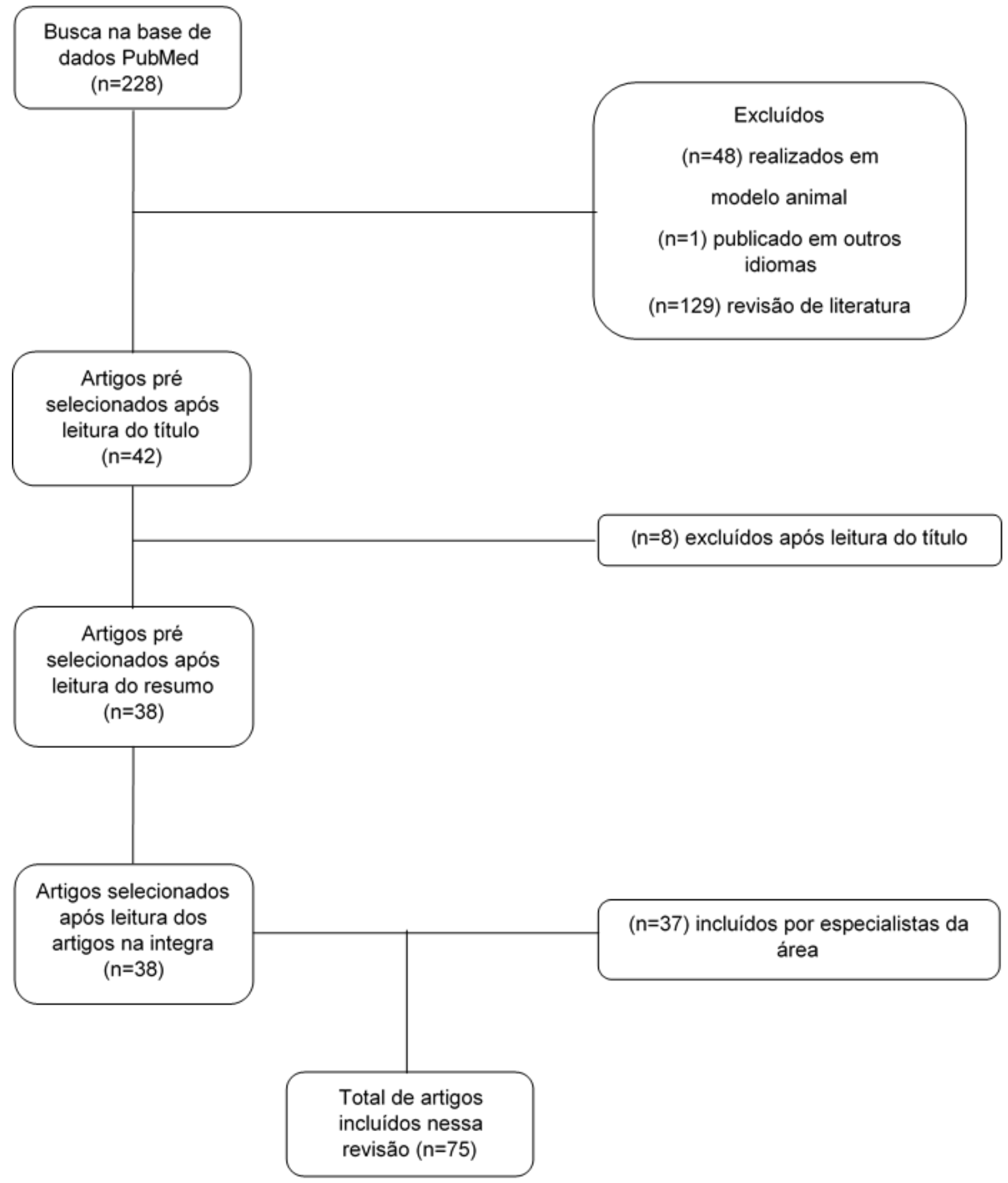

Figura 1. Fluxograma sistematizado da busca dos artigos. 


\section{RESULTADOS}

Inicialmente foram identificados 228 estudos na base de dados PUBMED utilizando as palavras chave descritas anteriormente, após uso dos critérios de seleção (humanos=180; inglês $=179$ e artigos originais=50) foram selecionados 50 artigos do PubMed. Após leitura dos títulos e resumos oito artigos foram excluídos por não estarem diretamente relacionados com o tema da revisão ou possuírem algum tipo de intervenção medicamentosa não condizente com o objetivo deste estudo. 37 artigos sugeridos por experts da área foram incluídos nesse estudo pela relevância e compatibilidade com o objetivo deste estudo. Ao final desta etapa restaram 75 trabalhos que foram lidos na íntegra e selecionados para esta revisão sistemática, como mostrado no fluxograma (figura 1).

Os estudos analisados envolveram 657 sujeitos, sendo 552 homens e 105 mulheres, com idades variando de 18 a 65 anos. Em relação a posição corporal, $30 \%$ dos protocolos foram realizados na posição sentada; $22 \%$ na posição semi-recumbente e $43 \%$ na posição supina. Quanto ao resultado obtido mediante análise dos artigos incluídos nessa revisão, observou-se que o metaborreflexo muscular não alterou os valores de repouso da FC na grande maioria dos estudos. Porém, cinco estudos que possuem em comum a posição semirecumbente, observaram um aumento da FC durante metaborreflexo em relação ao repouso, gerando assim questionamentos sobre os motivos que levaram a esses resultados (Fisher, et al.; 2008; Hartwich; 2011; Fisher et al. 2013; Drew, et 2015) (Tabela 1 e 2). 
Tabela 1. Exercício de preensão manual nas diferentes posições. M- masculino; F- feminino; \#- não possui informações; resposta da FC durante ativação Metaborreflexo em relação ao repouso; $\downarrow$ redução da FC; $\uparrow$ aumento da FC; não houve alteração de FC.

\begin{tabular}{|c|c|c|c|c|c|c|c|c|}
\hline & Estudo & $n$ & Sexo & Média/faixa & $\begin{array}{c}\text { Posição } \\
\text { do exercício }\end{array}$ & Intensidade & Tempo & Frequência \\
\hline
\end{tabular}

\begin{tabular}{|c|c|c|c|c|c|c|c|}
\hline \multirow{2}{*}{\multicolumn{8}{|c|}{ Sentada }} \\
\hline & & & & & & & \\
\hline lellamo, et al. 1994 & 16 & M & $27-46$ & Sentada & $30 \%$ & $2^{\prime}$ & $\leftrightarrow$ \\
\hline Spark, et al. 1998 & 10 & M & $24 \pm 1$ & Sentada & $30 \%$ & $2,5^{\prime}$ & $\leftrightarrow$ \\
\hline lellamo, et al. 1999 & 10 & M & 23-31 & Sentada & $30 \%$ & $3^{\prime}$ & $\leftrightarrow$ \\
\hline Williamson, et al.2003 & 16 & $8 \mathrm{M} 8 \mathrm{~F}$ & $26 \pm 3$ & Sentada & $30 \%$ & $3^{\prime}$ & $\leftrightarrow$ \\
\hline Turley, et al. 2005 & 35 & $M$ & $20 \pm 2$ & Sentada & $30 \%$ & $3^{\prime}$ & $\leftrightarrow$ \\
\hline Hjortskov, et al. 2005 & 9 & $4 \mathrm{M} 5 \mathrm{~F}$ & $37 \pm 6$ & Sentada & $30 \%$ & $3^{\prime}$ & $\leftrightarrow$ \\
\hline Clark, et al. 2008 & 9 & $4 \mathrm{M} / 5 \mathrm{~F}$ & $21 \pm 0.5$ & Sentada & $20 \%$ & \# & $\leftrightarrow$ \\
\hline Edwards,et al. 2008 & 14 & 9M5F & $23 \pm 5$ & Sentada & $30 \%$ & $1,5^{\prime}$ & $\leftrightarrow$ \\
\hline Ogoh, et al. 2009 & 9 & $M$ & $25 \pm 1$ & Sentada & $30 \%$ & $3^{\prime}$ & $\leftrightarrow$ \\
\hline Lykidis, et al. 2010 & 11 & 7M4F & $29 \pm 4.4$ & Sentada & $40 \%$ & $2^{\prime}$ & $\leftrightarrow$ \\
\hline Lykidis, et al. 2013 & 19 & 10M9F & $29 \pm 9$ & Sentada & $30 \%$ & $2^{\prime}$ & $\leftrightarrow$ \\
\hline Hayashi, et al. 2014 & 9 & $4 \mathrm{M} 5 \mathrm{~F}$ & $25 \pm 5$ & Sentada & $30 \%$ & $2^{\prime}$ & $\leftrightarrow$ \\
\hline \multicolumn{8}{|l|}{ Semi-recumbente } \\
\hline Sadamoto, et al.1994 & 10 & M & $21-31$ & Semi-recumbente & $20,33 \%$ e $50 \%$ & $2^{\prime}$ & $\leftrightarrow$ \\
\hline Nishiyasu, et al. 1998 & 8 & $M$ & $22 \pm 1$ & Semi-recumbente & $50 \%$ & $1^{\prime}$ & $\leftrightarrow$ \\
\hline Kondo, et al. 2003 & 21 & $M$ & $20.6 \pm 1.1$ & Semi-recumbente & $50 \%$ & $1^{\prime}$ & $\leftrightarrow$ \\
\hline Fisher, et al. 2008 & 8 & $7 \mathrm{M} 1 \mathrm{~F}$ & $24 \pm 1$ & Semi-recumbente & 35 e $45 \%$ & $2^{\prime}$ & $\leftrightarrow$ \\
\hline Fisher, et al. 2010 & 9 & M & $23 \pm 5$ & Semi-recumbente & 25 e $40 \%$ & $2^{\prime}$ & $\uparrow$ \\
\hline Fisher, et al. 2013 & 8 & $M$ & $22 \pm 3$ & Semi-recumbente & $25 \%$ & $3^{\prime}$ & $\uparrow$ \\
\hline Mcnulty, et al. (a) 2014 & 10 & M & $20 \pm 1$ & Semi-recumbente & $25 \%$ & $3^{\prime}$ & $\leftrightarrow$ \\
\hline holwerda, et al. 2015 & 10 & $5 \mathrm{M} 5 \mathrm{~F}$ & $46 \pm 3$ & Semi-recumbente & 30 e $40 \%$ & $2^{\prime}$ & $\leftrightarrow$ \\
\hline \multicolumn{8}{|l|}{ Supina } \\
\hline Shoemaker, et al. 2000 & 9 & $8 \mathrm{M} 1 \mathrm{~F}$ & $28 \pm 9(21-48)$ & Supina & $40 \%$ & $2^{\prime}$ & $\leftrightarrow$ \\
\hline Notarius, et al. 2001 & 10 & $9 \mathrm{M} 1 \mathrm{~F}$ & $48 \pm 4$ & Supina & $30 \%$ & $2^{\prime}$ & $\leftrightarrow$ \\
\hline Kamiya, et al. 2001 & 22 & $M$ & $22 \pm 2$ & Supina & $30 \%$ & $2^{\prime}$ & $\leftrightarrow$ \\
\hline Doerzbacher and Ray (a) & 21 & 14M7F & $19-33$ & Supina & $30 \%$ & $\#$ & $\leftrightarrow$ \\
\hline Cui, et al. 2001 & 11 & $8 \mathrm{M} 3 \mathrm{~F}$ & $32 \pm 2$ & Supina & $40 \%$ & $2^{\prime}$ & $\leftrightarrow$ \\
\hline Houssiere, et al. 2006 & 12 & $M$ & $23 \pm 2$ & Supina & $30 \%$ & $3^{\prime}$ & $\leftrightarrow$ \\
\hline Kuipers, et al. 2006 & 15 & 8M7F & $25 \pm 1$ & Supina & $30 \%$ & $2^{\prime}$ & $\leftrightarrow$ \\
\hline Gujic, et al. 2007 & 15 & M & $25 \pm 1$ & Supina & $30 \%$ & $3^{\prime}$ & $\leftrightarrow$ \\
\hline Momen, et al. 2007 & 11 & $8 \mathrm{M} 3 \mathrm{~F}$ & $25 \pm 1$ & Supina & $30 \%$ & * & $\leftrightarrow$ \\
\hline Cui, et al. 2007 & 12 & $8 \mathrm{M} 4 \mathrm{~F}$ & $25 \pm 1$ & Supina & $30 \%$ & $2^{\prime}$ & $\leftrightarrow$ \\
\hline Park, et al. 2008 & 16 & M & $31 \pm 1$ & Supina & $30 \%$ & $3^{\prime}$ & $\leftrightarrow$ \\
\hline Padilla, et al. 2010 & 14 & $M$ & $25 \pm 1$ & Supina & $35 \%$ & $2^{\prime}$ & $\leftrightarrow$ \\
\hline Sander, et al. 2010 & 17 & $9 \mathrm{M} 8 \mathrm{~F}$ & $19-46$ & Supina & $40 \%$ & $2^{\prime}$ & $\leftrightarrow$ \\
\hline Belloka, et al. 2011 & 23 & M & $23 \pm 2.3$ & Supina & $30 \%$ & $3^{\prime}$ & $\leftrightarrow$ \\
\hline Cui, et al. 2011 & 10 & $9 \mathrm{M} 1 \mathrm{~F}$ & $25 \pm 1$ & Supina & $30 \%$ & * & $\leftrightarrow$ \\
\hline kiviniemi, et al. 2011 & 13 & 9M4F & $27 \pm 2$ & Supina & $20 \%$ & $5^{\prime}$ & $\leftrightarrow$ \\
\hline Mcgowan, et al. 2011 & 17 & $M$ & $31 \pm 11$ & Supina & 30 e $50 \%$ & $2^{\prime}$ & $\leftrightarrow$ \\
\hline kiviniemi, et al. 2012 & 13 & 9M4F & $27 \pm 3$ & Supina & $20 \%$ & $5^{\prime}$ & $\leftrightarrow$ \\
\hline Fernandes, et al. 2014 & 8 & M & $30 \pm 2$ & Supina & $25 \%$ & $3^{\prime}$ & $\leftrightarrow$ \\
\hline Greaney, et al. 2014 & 13 & $M$ & $63 \pm 2$ & Supina & $40 \%$ & $2^{\prime}$ & $\leftrightarrow$ \\
\hline Delliaux, et al. 2015 & 10 & M & $24 \pm 1$ & Supina & $50 \%$ & $1^{\prime}$ & $\leftrightarrow$ \\
\hline
\end{tabular}




\section{Ex. dinâmico de preensão manual}

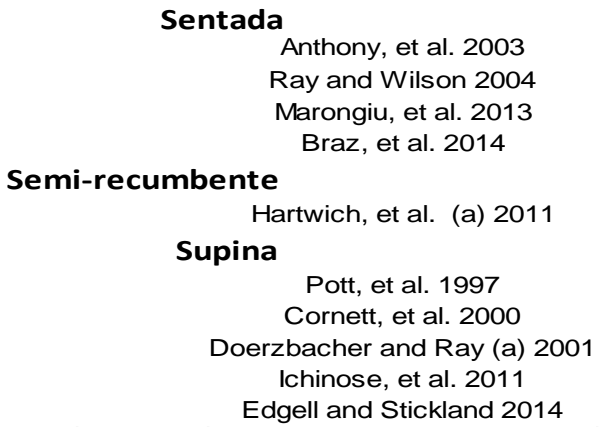

$\begin{array}{cc}16 & 10 \mathrm{M} 6 \mathrm{~F} \\ 10 & \mathrm{M} \\ 10 & \mathrm{M} \\ 10 & \mathrm{M}\end{array}$

$25 \pm 2.1$
$18-25$
$34 \pm 1$
$20 \pm 1$
$23 \pm 4$

$26 \pm 1$
$23 \pm 1$
$19-33$
$25 \pm 1$
$25 \pm 1$

Sentada

Sentada

Sentada

Sentada

$\#$
$30 \%$
$30 \%$
$40 \%$

$1^{\prime}$
$2^{\prime}$
$3^{\prime}$

$1^{\prime}$
$2^{\prime}$
$3^{\prime}$
$3^{\prime}$

semi-recumbente

$35 \%$

$17,5^{\prime}$

$20 \%$

$15-60 \%$

$30 \%$

$15 \%$

$40 \%$ $\leftrightarrow$

$\leftrightarrow$

$\leftrightarrow$

$\leftrightarrow$

$\begin{array}{ccc}M & 23 \pm 1 & \text { Supina } \\ 14 M 7 F & 19-33 & \text { Supina } \\ \text { 9M2F } & 25 \pm 1 & \text { Supina } \\ \text { M } & 25 \pm 1 & \text { Supina }\end{array}$

Tabela 2. Exercício membros inferiores nas diferentes posições. M- masculino; F- feminino; \#- não possui informações; resposta da FC durante ativação Metaborreflexo em relação ao repouso; $\downarrow$ redução da FC; $\uparrow$ aumento da FC; não houve alteração de FC.

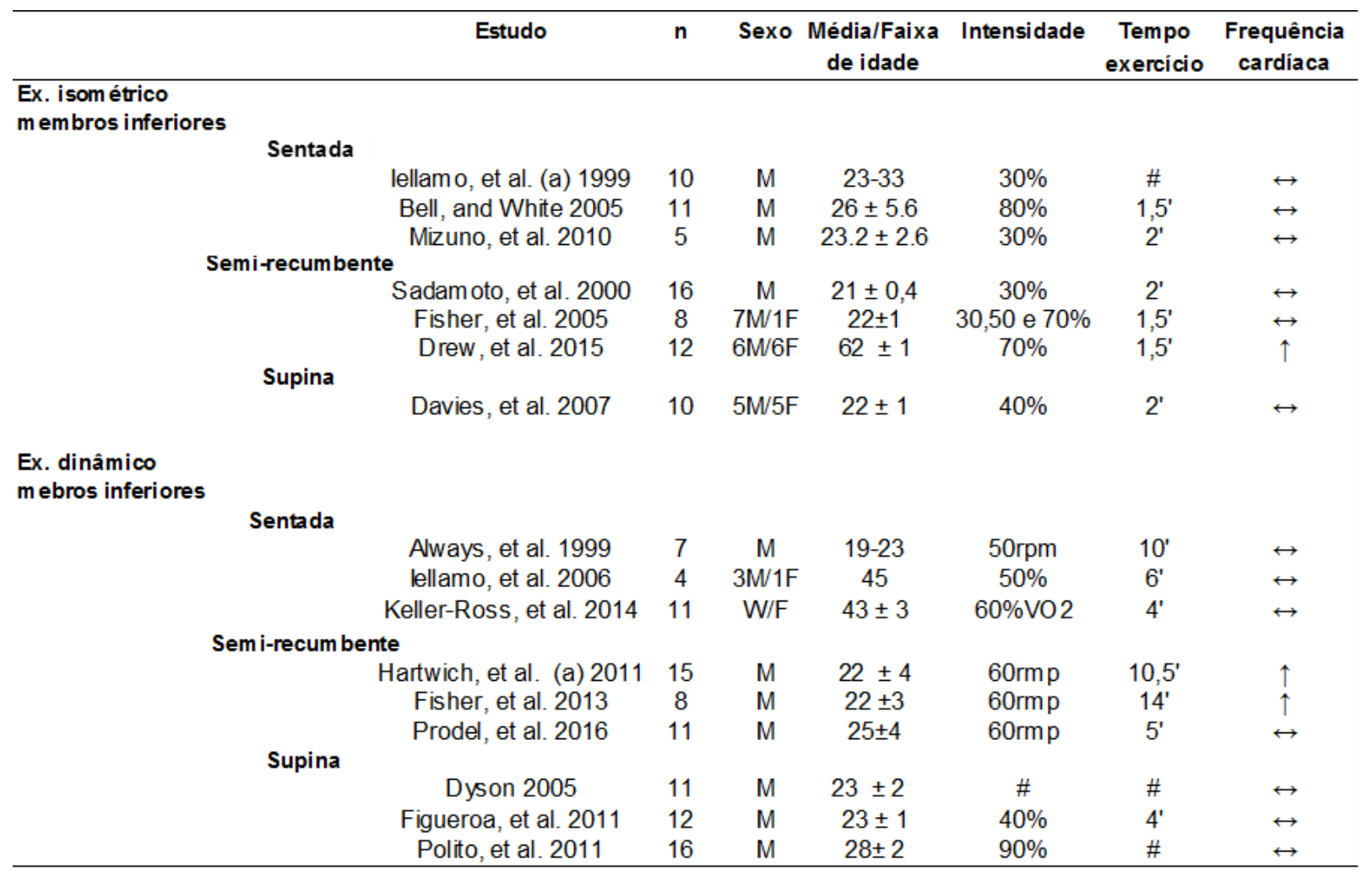

\section{DISCUSSÃO}

Em nosso conhecimento, essa foi a primeira revisão sistematizada realizada com 0 objetivo de identificar o impacto da ativação do metaborreflexo muscular na regulação da FC 
em humanos. Os resultados da maioria dos estudos mostraram que, durante ativação do metaborreflexo muscular a FC não apresenta mudanças significativas em relação aos valores de repouso.

A ativação seletiva do metaborreflexo é uma técnica em que o manguito é inflado em torno do membro em exercício a um nível supra sistólico, segundos antes do final do exercício, fazendo o aprisionamento de metabólitos no músculo (Alam e Smirk,1937). Acredita-se que, a ativação do metaborreflexo aumenta a atividade simpática, no entanto a resposta da PA é dependente do modo de ativação do metaborreflexo, podendo ser atribuível tanto ao DC (O'Leary e Augustyniak, 1998; Crisafulli, et al. 2003; Sala-Mercado, et al. 2006; Crisafulli, et al. 2011) como a RPT (Bastos, et al. 2000; Lykidis, et al. 2008).

Toda via, o foco deste estudo concentra-se nas respostas da FC. Estudos apontam que durante ativação metaborreflexa, a FC retorna rapidamente aos valores de repouso, sugerindo que o metaborreflexo possui pouca influência sobre o coração (Freund, et al. 1978; Mark, et al., 1985; Victor, et al 1987; Rowell e O'Leary, 1990). Esse retorno da FC para valores próximos ao repouso durante a ativação do metaborreflexo muscular ocorre segundo alguns autores devido a reativação do sistema nervoso parassimpático (O'Leary, 1993; Fisher, et al. 2010). Considerando assim, que durante OCPE ocorre ativação do barroreflexo e a perda do efeito inibitório do comando central e do mecanorreflexo muscular (O'Leary, 1993; Nishiyasu, et al. 1994; lellamo, et al. 1999; Fisher, et al. 2010).

Reafirmando os achados dos estudos incluídos nessa revisão, em um de seus estudos, lellamo et al. (1999) comparou exercício isométrico de preensão manual a 30\% CVM ao exercício de extensão de perna 15 e 30\% da CVM em 16 homens, e concluiu que a magnitude 
da massa muscular durante o exercício estático afeta a resposta cardiovascular. No entanto os autores não observaram alterações na FC durante ativação do metaborreflexo muscular.

Inúmeros estudos afirmam que apesar da atividade nervosa simpática estar elevada durante ativação do metaborreflexo, a mesma não influencia na FC. Entretanto, Fisher, et al. (2010) afirmam que uma ativação mais robusta de metaborreflexo pode ter efeito sobre a FC por meio do aumento da atividade nervosa simpática e atenuação da reativação parassimpática. O aumento da ativação do metaborreflexo é acompanhado pelo aumento da necessidade metabólica dos músculos e da resposta cardiovascular integrada (Mcnulty, 2014). Deste modo, alguns estudos que realizaram exercício na posição semi-recumbente observaram um aumento significativo da FC em relação ao momento de repouso (Fisher, et al.; 2008; Fisher, et al.; 2010; Hartwich, et al.; 2011; Fisher, et al. 2013; Drew, et al.; 2015).

A partir dos resultados dessa revisão é possível observar uma vasta variação nos protocolos utilizados durante o método de ativação isolada do metaborreflexo muscular, como, intensidade de ativação, tempo de oclusão circulatória, mistura de gêneros e diferentes posicionamentos corporais. Em síntese, estudos como de Fisher, et al. (2005) encontraram diferenças significativas na resposta da FC durante ativação do metaborreflexo muscular na posição semi-recumbente, porém a maioria dos estudos não encontraram diferença na resposta da FC durante ativação metaborreflexo em relação ao período de repouso. 


\title{
3. ESTUDO 2
}

\section{Artigo original}

\section{AFERÊNCIAS CARDIOPULMONARES MODULAM A RESPOSTA SIMPÁTICA DA FREQUÊNCIA CARDÍACA POR MEIO DA ATIVAÇÃO DO METABORREFLEXO MUSCULAR EM HUMANOS}

\author{
Mayara C. Souza ${ }^{1}$ \\ André L. Teixeira ${ }^{1}$ \\ Diego Antonino ${ }^{1}$ \\ Paulo M. Maia-Lopes ${ }^{1}$ \\ Plinio S. Ramos ${ }^{1,2}$ \\ Lauro C. Vianna ${ }^{1}$
}

1 - Faculdade de Educação Física, Universidade de Brasília (UnB), Brasília, DF, Brasil.

2 - Hospital e maternidade Therezinha de Jesus, Faculdade de Ciências Médicas e da Saúde (SUPREMA), Juiz de Fora, MG, Brasil.

\section{Correspondência:}

Dr. Lauro C. Vianna, PhD

Laboratório de Fisiologia Integrativa- NeuroVASQ

Faculdade de Educação Física

Universidade de Brasília

Campus Darcy Ribeiro, Brasília, Brasil

tel: (61) 31072531

Fax: (61) 31072512

Email: Icvianna@unb.br 


\section{OBJETIVO}

Testar a hipótese de que a resposta simpática da FC mediada pela ativação do metaborreflexo muscular é anulada pela ativação dos receptores cardiopulmonares em humanos através de mecanismos $\beta$-1 adrenérgico.

\section{MÉTODOS}

\section{AMOSTRA}

Para o protocolo 1, 19 homens saudáveis (média \pm erro padrão da média (EPM): idade $20 \pm 2$ anos) integrantes do corpo estudantil da Universidade de Brasília foram selecionados para participar do estudo. Um subgrupo de cinco participantes foram selecionados para participar do protocolo 2. Foram considerados como critérios de exclusão o diagnóstico ou evidência de qualquer doença cardiovascular, metabólica, ortopédica, neurológica ou endócrina; o uso de qualquer medicação que pudesse interferir na função cardiovascular; tabagismo e risco de respostas adversas ao exercício. Nenhum indivíduo reportou o diagnóstico de doenças ou a utilização de medicamentos que afetem o sistema cardiovascular.

Após contemplar aos critérios de inclusão dos estudos, os voluntários foram orientados e incluídos na pesquisa após a assinatura do Termo de Consentimento Livre e Esclarecido (Anexo 1).

Os indivíduos foram orientados a abster-se de bebidas alcoólicas e cafeína por, no mínimo, 24h horas que antecederam a participação no estudo, assim como, 12h sem realizar 
atividades físicas. Todos os protocolos utilizados no presente estudo foram aprovados pelo Comitê de Ética em Pesquisa da Universidade de Brasília (CAAE: 45158615.3.0000.0030) e estão de acordo com a Resolução no 466/912 do Conselho Nacional de Saúde (CNS) que regulamenta as pesquisas envolvendo seres humanos.

\section{Teste de força de preensão manual máxima}

Para determinação da força de preensão manual os sujeitos realizaram três contrações voluntárias máximas (CVM) com o braço dominante, usando um dinamômetro mecânico (JAMAR- SH5001) com intervalos de um minuto entre cada contração. Os sujeitos foram instruídos a realizar o máximo de força possível durante três segundos e a maior força exercida das três medidas foi considerada como a CVM para o cálculo de 40\% CVM.

\section{Protocolo 1.}

Após o teste, os sujeitos descansaram por 15 minutos, enquanto o cuff do fotoplestimiógrafo, foi ajustado ao dedo médio da mão não dominante e um manguito com esfigmomanômetro foi colocado ao redor do braço dominante para realização da OCPE. Dados de repouso foram registrados durante três minutos que antecederam o início do exercício. Os dados foram obtidos durante $1 \frac{1}{2} 2$ minuto de exercício isométrico de preensão manual a $40 \%$ da CVM, seguido por oclusão circulatória através da insuflação de um manguito pneumático durante os 30 segundos finais do exercício. A oclusão foi mantida por três minutos a valores supra sistólicos (>250mmHG).

Os participantes foram orientados a respirar normalmente e de forma constante durante todo procedimento. 


\section{Protocolo 2.}

Um subgrupo de sujeitos $(n=5)$ repetiu os protocolos com bloqueio $\beta$-adrenérgico no coração por meio da ingestão de um betabloqueador seletivo (Atenolol $25 \mathrm{mg}$ ). Este medicamento administrado por via oral tem sua ação iniciada uma hora após sua ingestão, atingindo seu máximo entre duas e quatro horas após a ingestão. Os indivíduos participantes do bloqueio compareceram ao NeuroVASQ duas horas antes do início do protocolo de preensão manual para fazerem a ingestão do medicamento assim como as aferições iniciais de FC e PA. Os sujeitos permaneceram no laboratório durante todo o procedimento. Após $1 \mathrm{~h}$ da ingestão da droga, foi dado prosseguimento ao protocolo dois, seguindo os procedimentos já descritos no protocolo um.

A figura 2, ilustra os procedimentos realizados nesse estudo

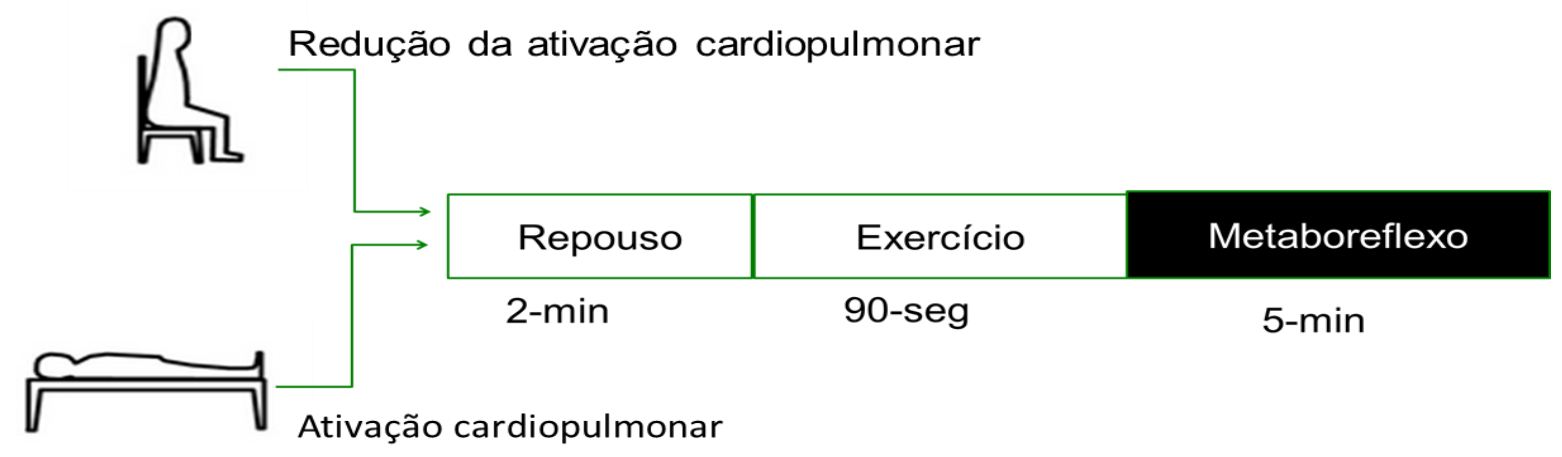

Figura 2. Procedimentos experimentais.

\section{Variáveis hemodinâmicas}

A FC foi mensurada por um eletrocardiograma de três derivações (Finometer, Finapres, Holanda). A PA foi mensurada, batimento-a-batimento pelo método de fotopletismografia, 
posicionando um manguito (Finometer, Finapres, Holanda) de tamanho apropriado no dedo médio da mão contralateral ao exercício.

\section{Análise dos dados}

Considerou-se como variável principal a resposta pressórica ao exercício, apresentando uma variabilidade de resposta de 12\%, uma diferença de resposta entre os tratamentos (Sentado vs. Deitado) equivalente a $10 \mathrm{mmHg}$, um poder de 0,8, um erro alfa de 0,05 e um tamanho do efeito de 0,7 através da equação de Cohen's-d.

Os dados foram tratados inicialmente mediante procedimentos descritivos. O teste de Shapiro-Wilk foi utilizado para avaliação da normalidade dos dados. Quando essa condição foi confirmada, a ANOVA com medidas repetidas foi utilizada para comparar as variáveis cardiovasculares. A esfericidade dos dados foi verificada por meio do teste de Mauchly, e quando esta não foi assumida, foi adotada a correção de Greenhouse-Geisser. Foi utilizado o teste post hoc Fisher's LSD para a identificação pontual das diferenças. A significância das análises foi assumida quando $P \leq 0,05$.

\section{RESULTADOS}

As características iniciais dos sujeitos estão apresentadas na tabela 3 . Todos os sujeitos completaram o protocolo de exercício, a percepção subjetiva de esforço (PSE) média relatada pelos sujeitos foi de oito (difícil) imediatamente antes da OCPE. 
Tabela 3. Caracterização da amostra $(n=19)$.

\begin{tabular}{lccc}
\hline & Média & & EPM \\
\hline Idade (anos) & 20 & \pm & 2 \\
Altura $(\mathrm{cm})$ & 180 & \pm & 1 \\
Massa Corporal $(\mathrm{kg})$ & 73 & \pm & 13 \\
IMC $\left(\mathrm{kg} / \mathrm{m}^{2}\right)$ & 25 & \pm & 1,4 \\
MVC Braço dominante $(\mathrm{N})$ & 454 & \pm & 102,3 \\
\hline
\end{tabular}

Valores apresentados como média \pm erro padrão da média.

Em repouso, a mudança da postura supina para postura sentada promove aumento da FC de $64 \pm 2$ a $69 \pm 2$ bpm $(p<0,05)$, enquanto a PA diminuiu de $90 \pm 2$ a $84 \pm 2 \mathrm{mmHg}(p<0,05)$. OCPE provocaram um aumento robusto PA de repouso $(\Delta 36 \pm 3 \mathrm{mmHg}, \mathrm{p}<0,05)$, que não foi afetada pela postura corporal.

TABELA 4. Variáveis cardiovasculares em repouso

\begin{tabular}{|c|c|c|c|}
\hline & & Protocolo $1(n=19)$ & Protocolo $2(n=5)$ \\
\hline \multicolumn{4}{|c|}{$\mathrm{FC}(\mathrm{bpm})$} \\
\hline & Sentado & $69 \pm 2$ & $47 \pm 6^{*} \dagger$ \\
\hline & Supino & $64 \pm 2^{*}$ & $43 \pm 5^{*} \dagger$ \\
\hline \multicolumn{4}{|c|}{ PAM $(\mathrm{mmHg})$} \\
\hline & Sentado & $84 \pm 1.6$ & $105 \pm 5 \dagger$ \\
\hline & Supino & $90 \pm 1.6^{*}$ & $109 \pm 4^{*} \dagger$ \\
\hline \multicolumn{4}{|c|}{ PAS $(\mathrm{mmHg})$} \\
\hline & Sentado & $118 \pm 2$ & $113 \pm 3 \dagger$ \\
\hline & Supino & $125 \pm 2^{*}$ & $116 \pm 2^{*} \dagger$ \\
\hline \multicolumn{4}{|c|}{ PAD $(\mathrm{mmHg})$} \\
\hline & Sentado & $67 \pm 1.7$ & $66 \pm 5 \dagger$ \\
\hline & Supino & $73 \pm 1.6^{*}$ & $69 \pm 3^{*} \dagger$ \\
\hline
\end{tabular}


Durante postura sentada OCPE, a frequência cardíaca foi elevada a partir do repouso ( $\Delta 2 \pm 2$ bpm, $p>0,05$ vs. repouso). Seguindo $\beta-1$ bloqueio adrenérgico, a resposta da FC na postura sentada para OCPE foi significativamente reduzida ( $\Delta 5 \pm 3 \mathrm{bpm}, p<0,05)$, enquanto a resposta da FC e na postura supina OCPE não foi afetada ( $\Delta 3 \pm 2 \mathrm{bpm}$ ) (figura 3 e 4 ).

As respostas de FC e PA podem ser observadas na figura 3 e na figura 4 que se referem aos resultados dos indivíduos que realizaram com bloqueio farmacológico.

\section{Protocolo 1.}
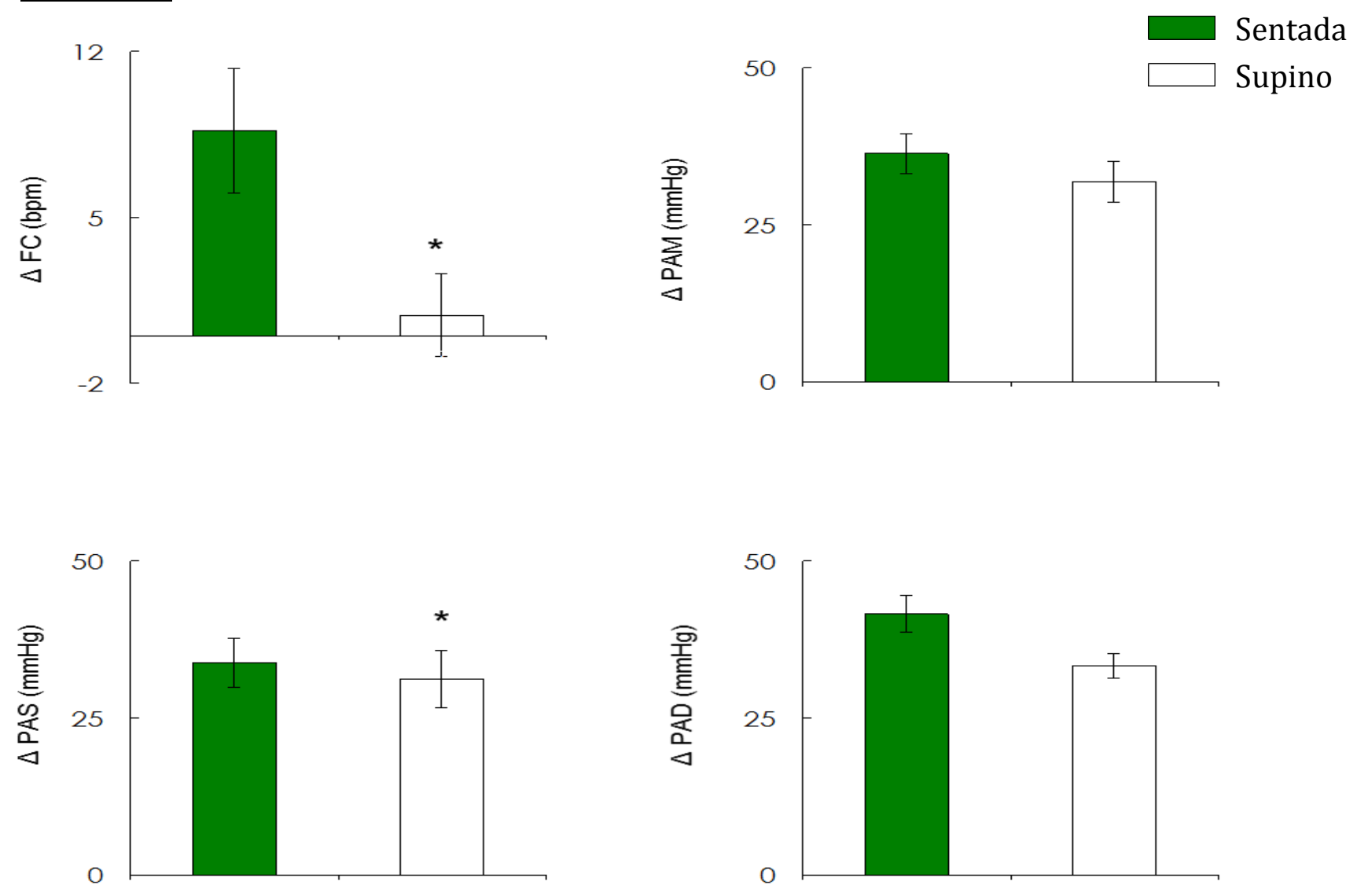

Figura 3. Resultados variáveis hemodinâmicas protocolo exercício isométrico. FC: Frequência cardíaca; PAM: pressão arterial média; PAS: pressão arterial sistólica; PAD: pressão arterial diastólica; $\Delta$ : delta. 


\section{Protocolo 2.}
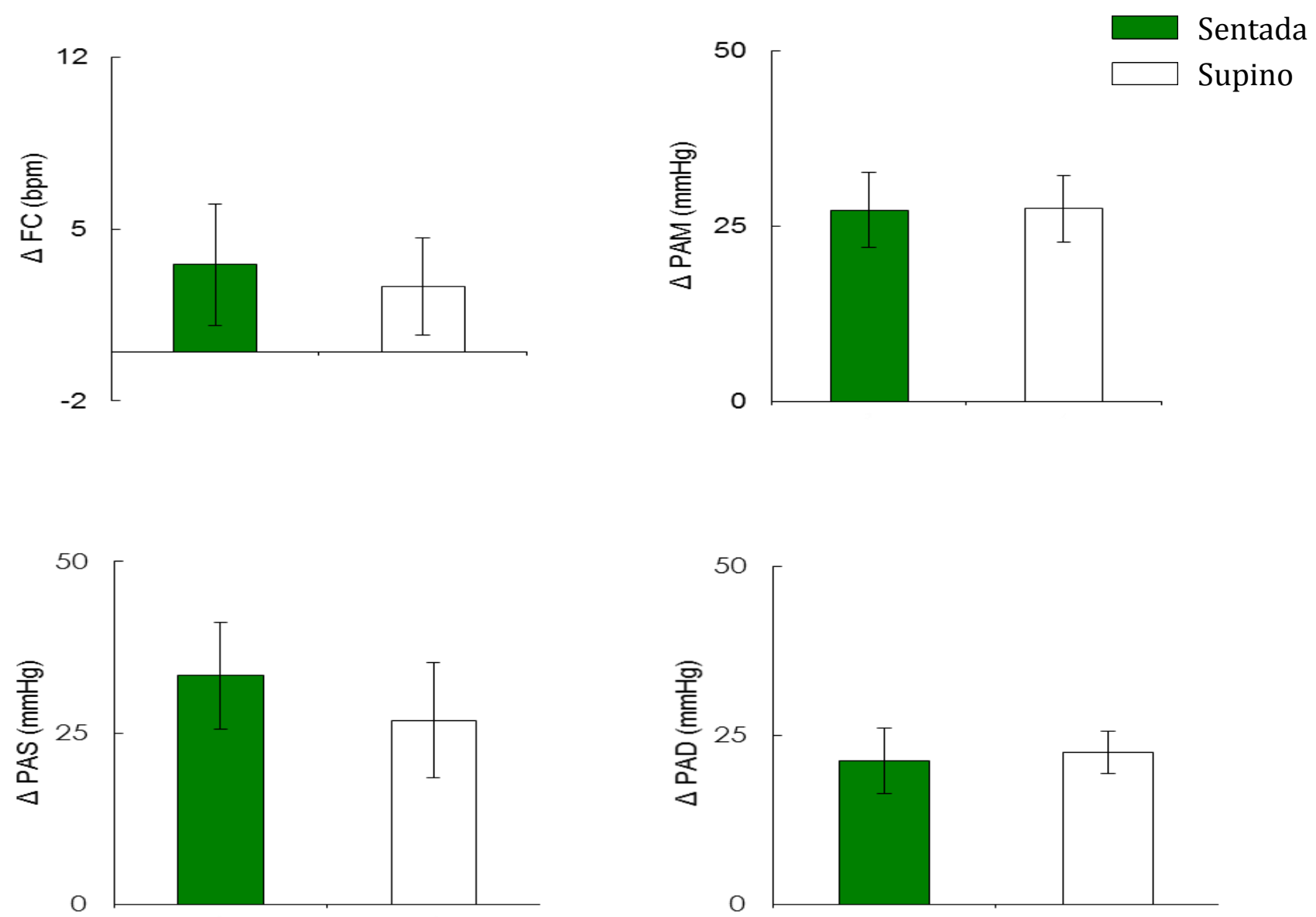

Figura 4. Resultados variáveis hemodinâmicas protocolo exercício isométrico + bloqueio $\beta-1$. FC: Frequência cardíaca; PAM: pressão arterial média; PAS: pressão arterial sistólica; PAD: pressão arterial diastólica; $\Delta$ : delta.

\section{DISCUSSÃO}

Existe uma escassez de informações acerca das influências do barorreceptor cardiopulmonar durante ativação do metaborreflexo muscular na resposta da FC. Assim, conclusões acerca desse assunto devem ser tomadas observando-se a forma de ativação cardiopulmonar e como ela influência nas respostas.

Os barorreceptores cardiopulmonares são estimulados por meio de mudanças de pressão nas câmeras cardíacas, localizado nos átrios, ventrículos e vasos pulmonares, esses receptores são conectados ao SNC, sistema nervoso simpático e a medula espinhal. Além de 
possuir vasta localização, os sinais desses barorreceptores são distribuídos por diferentes fibras aferentes, vagais ou simpáticas, tendo a aferências vagal com maior predominância (Thoren, 1972; Thoren, 1976; Ustinova \& Schultz, 1994).

O metaborreflexo muscular envia aferências simpato-excitatórias ao núcleo do trato solitário (NTS), responsável por conduzir estímulos simpáticos ao coração, enquanto os receptores cardiopulmonares fazem o envio de estímulos simpato-inibitórios ao NTS, que determinam as respostas hemodinâmicas durante ativação de ambos os mecanismos. A ativação dos receptores cardiopulmonares aumenta a quantidade de aferências inibitórias, dando assim aporte a hipótese inicial desse estudo, de que durante a ativação dos receptores cardiopulmonares em conjunto com ativação do metaborreflexo muscular tem-se um aumento dos estímulos parassimpático e redução dos estímulos simpáticos fazendo com que ocorra uma redução na FC. Em contrapartida, quando os receptores cardiopulmonares são inibidos, ocorre uma resposta inversa, com redução dos estímulos parassimpáticos e aumento da atividade simpática no coração promovendo um aumento de FC (Figura 5) (Fisher, et al., 2015). 


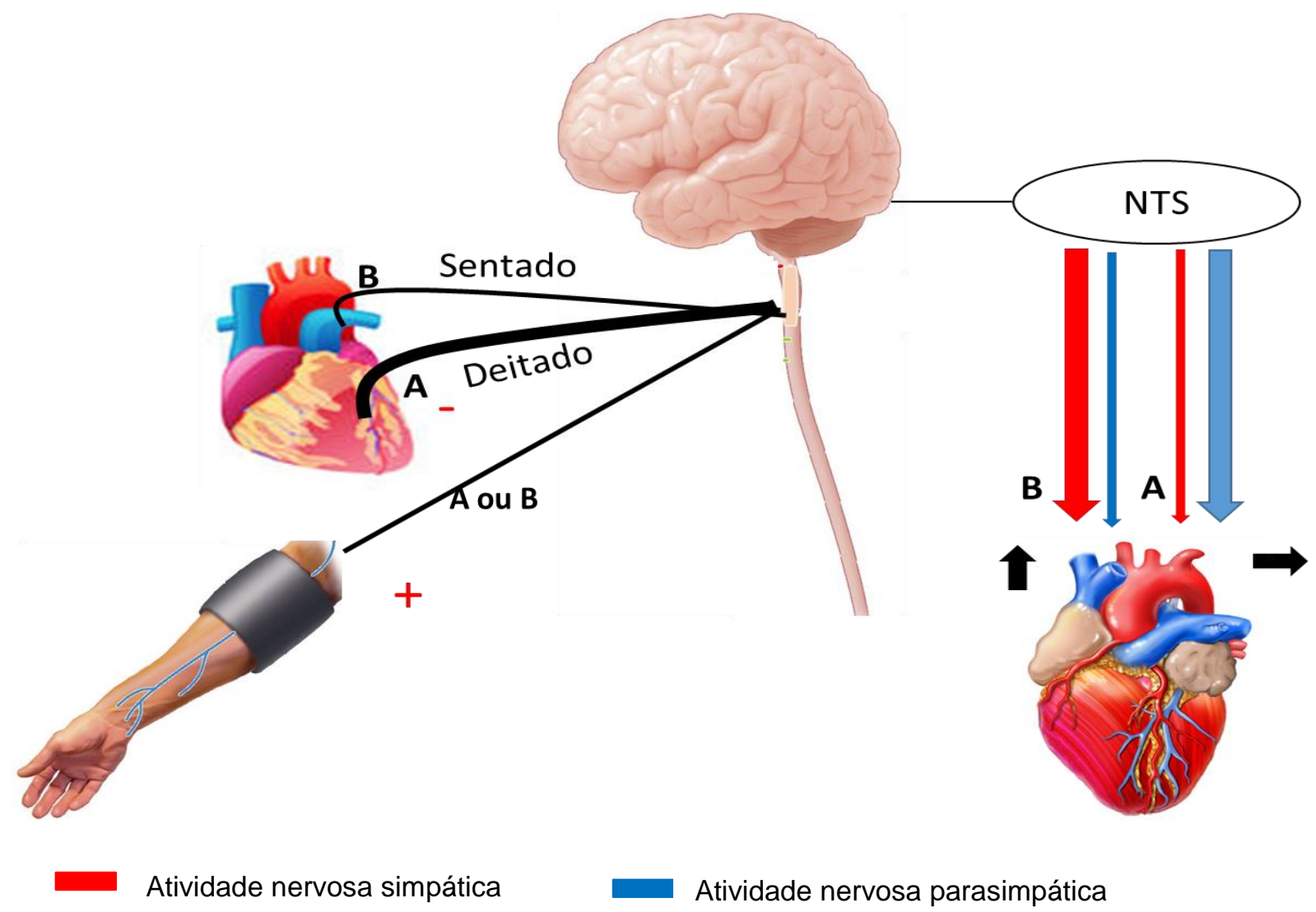

Figura 5. Esquema demonstrando as aferências provenientes da ativação do Metaborreflexo muscular e da ativação e redução da ativação dos barorreceptores cardiopulmonares. NTS- núcleo do trato solitário; A- posição sentado; B posição deitado; sem alteração de FC, aumento de FC.

Em humanos, os barorreceptores cardiopulmonares podem ser estimulados a partir de manobras que manipulem o volume sanguíneo central. Estudos utilizam como instrumento auxiliar uma caixa de pressão negativa que possui como principal função diminuir o retorno venoso em situações programadas. Alguns estudos também apontam com estratégia de ativação ou desativação do reflexo cardiopulmonar a mudança de postura, sendo este método uma forma fácil e eficaz de manipulação dos receptores cardiopulmonares. Estudo como o de McDonald, et al. (1988) e Hughson, et al. (1991) compararam exercício na posição supino e ortostática e não observaram alterações significativas na FC. 
Uma menor resposta na FC pode ser evocada através do bloqueio farmacológico do receptor $\beta$-1 adrenérgico. Uma carga dos receptores cardiopulmonares associado a posição supina, também fornece sinais neuromoduladores ao tronco cerebral o que pode provocar inibição simpática cardíaca, estando de acordo com os achados no presente estudo, o qual a resposta da FC durante a ativação isolada do metaborreflexo muscular é aumentada pela inibição dos barorreceptores cardiopulmonares devido ao mecanismo b-1 adrenérgico.

Em resumo, o presente estudo demonstra que a resposta da frequência cardíaca durante a ativação isolada do metaborreflexo muscular é aumentada pela inibição dos barorreceptores cardiopulmonares devido a um mecanismo $\beta-1$ adrenérgico.

\section{CONCLUSÕES}

Ainda que, os resultados obtidos por meio da revisão sistemática demonstrem uma certa contradição nos achados sobre a regulação da FC durante ativação do metaborreflexo muscular. O estudo original realizado, demonstra que a resposta da frequência cardíaca durante a ativação isolada do metaborreflexo muscular é aumentada pela inibição dos barorreceptores cardiopulmonares (posição sentada) devido a um mecanismo $\beta-1$ adrenérgico.

\section{REFERÊNCIAS BIBLIOGRÁFICAS}


Aboab, J.; Sebille, V., Jourdain, M. Effects of esmolol on systemic and pulmonary hemodynamics and on oxygenation in pigs with hypodynamic endotoxin shock. Intensive Care Medicine.v.37, n.8, p.1344-1351, 2011.

Alam, M.; Smirk, F. H. Observations in man upon a blood pressure raising reflex arising from the voluntary muscles. J Physiol.v. 89, n.4, p. 372-83, 1937.

Always, S. E.; Hughson, R. L.; Green, H. J.; Patia, A. E. Human tibialis anterior contractile responses following fatiguing with and without $\beta$-adrenoceptor blockade. Clinical Physiology, v. 8, p.215-225, 1988.

Anthony, B.; Boudreaux, L.; Dobbs, I.; Jamal, S.; Guerra, P.; Williamson, J. W. Can relaxation lower metaboreflex mediated blood pressure elevations?. Medicine e science in sports e exercise, v.35, n.3, p. 394-399, 2003.

Bastos, B. G.; Williamson, J. W.; Harrelson, T.; Nobrega, A. C. L. Left ventricular volumes and hemodynamic responses to postexercise ischemia in healthy humans. Medicine e science in sports e exercise, v. 2, n.6, p. 1114-1118, 2000.

Bell, M. P. D.; White, M. J. Cardiovascular responses to external compression of human calf muscle vary during graded metaboreflex stimulation. Exp. Physiol., v.90, n.3, p.383-391, 2005.

Beloka, S. P.; Jamsen, C.; Wolf, E.; Brassine, E.; Deboeck, G.; Randria, J.; Foy, V.P.; Borne, P. V., Naeije, R. Effects of $\beta 2$-adrenergic stimulation on exercise capacity in normal subjects. Eur. J. appl physiol., v. 111, p. 2239-247, 2011.

Braz, I. D.; Scott, C.; Simpson, E. L. Influence of muscle metaboreceptor stimulation on middle cerebral artery blood velocity in humans. Exp. Physiol., v.99, n.11, p. 1478-1487, 2014. 
Carrington, C. A.; Ubolsakka, C.; White, J. M. Interaction between muscle metaboreflex modulation of arterial baroreflex sensitivity in human exercise. J. appl. Physiol. v. 95, n.1, p.4348, 2003.

Clark, B. C.; Hoffman, R. L.; Russ, D. W. Immobilization induced increase in fatigue resistance is not explained by changes in the muscle metaboreflex. Muscle nerve, v. 38, n. 5, p. 1466-1473, 2008.

Cornett, J. A.; Herr, M. D.; Gray, K. S.; Smith, M. B.; Yang, Q. X.; Sinoway, L. I. Ischemic exercise and the muscle metaboreflex. J. appl. Physiol., v.89, p.1432-1436, 2000.

Crisafulli, A.; Tocco, F.; Milia, R.; Angius, L.; Pinna, M.; Olla, S.; Roberto, S.; Marongiu, E.; Porcu, M.; Concu, A. Progressive improvement in hemodynamic response to muscle metaboreflex in heart transplant recipients. J. Appl. Physiol., v.114, p. 421-427, 2012.

Cui, J.; Leunberger, U. A.; Blaha, C.; King, N. C.; Sinoway, L. I. Effect of P2 receptor blockade with pyridoxine on sympathetic response to exercise pressor reflex in humans. J. Phisiol., v.589, n. 3, p. 685-695, 2011.

Cui, J.; Mcquillan, P.; Momen, A.; Blaha, C.; Moradkhan, R.; Mascarenhas, V.; Hogeman, C.; Krishnan, A.; Sinoway, L. I. The role of the cyclooxygenase products in evoking sympathetic activation in exercise. Am. J. Physiol. heart circ. Physiol., v.293, p. H1861-H1868, 2007.

Cui, J.; Wilson, T. E.; Shibasaki, M.; Hodges, N. A.; Crandall, C. G. Baroreflex modulation of muscle sympathetic nerve activity during posthandgrip muscle ischemia in humans. J. appl. Physiol., v.91, p. 1679-1686, 2001. 
Dahle, G. O.; Salminen, P.R.; Moen, C. A.; Eliassen, F.; Jonassen, A. K.; Haaverstad, R. et al. Esmolol added in repeated, cold, oxygenated blood cardioplegia improves myocardial function after cardiopulmonary bypass. J Cardiothorac Vasc Anesth. v. 29, n.3, p.684-93, 2015.

Davies, T. S.; Frenneaux, M. P.; Campbell, R. I.; White, M. J. Human arterial response to isometric exercise: the role of the muscle metaboreflex. Clinical Science, v.112, p.441-447, 2007.

Delaney, E.P.; Greaney, J.L.; Edwards, D. G.; Rose, W.C.; Fadel, P. J.; Farquhar, W. B. Exaggerated sympathetic and pressor responses to handgrip exercise in older hypertensive humans: role of the muscle metaboreflex. Am J Physiol Heart Circ Physiol. v.299, n.5, p. H1318H1327, 2010.

Delliaux, S.; Ochinose, M.; Watanabe, K.; fujii, N.; Nishiyasu, T. Cardiovascular responses to forearm muscle metaboreflex activation during hypercapnia in humans. Am j. Physiol. regul. Inter. Comp. Physiol., v. 309, n.1, p. R43-R50, 2015.

Doerzbacher, K. J.; Ray, C. A. Muscle sympathetic nerve responses to physiological changes in prostaglandin production in humans. J. appl. Physiol., v.90, p. 624-629, 2001.

Drescher, U. et al. Analysis of cardio-pulmonary and respiratory kinetics in different body positions: impact of venous return on pulmonary measurements. Eur J Appl Physiol. v.116, p.1343-1353, 2016.

Drew, R. C.; Bell, M. P.; White, M.J. Modulation of spontaneous baroreflex control of heart rate and indexes of vagal tone by passive calf muscle stretch during graded metaboreflex activation in humans. J Appl Physiol. v.104, n. 3, p.716-723, 2008. 
Drew, R. C.; Mclntyre, D. B.; Ring, C.; White, M. J. Local metabolite accumulation augments passive muscle stretch-induced modulation of carotid-cardiac but not carotid-vasomotor baroreflex sensitivity in man. Exp Physiol.v. 93, n.9, p. 1044-57, 2008.

Drew, R. C.; Blaha, C. A.; Herr, M. D.; Sinoway, L. I. Healthy older humans exhibit augmented carotid-cardiac baroreflex sensitivity with aspirin during muscle mechanoreflex and metaboreflex activation. Am j. Physiol. heart circ. Physiol., v. 309, p. H1361-H1369, 2015.

Dyson, K. S.; Shoemaker, J. K.; Hughson, R. Effect of acute sympathetic nervous system activation on flow-mediated dilation of brachial artery. Am. J. Physiol. heart circ. Physiol., v. 290, p. H1446-H1453, 2006.

Edgell, H.; Stickland, M. K. Activation of the carotid chemoreflex secondary to muscle metaboreflex stimulation in men. Am. J. Physiol. Regul. Integr. Comp. Physiol, v.306, p.R693R700, 2014.

Edwards, D. G.; Mastin, C. R.; Kenefick, R. W. Wave refletion and central aortic pressure are increased in response to static and dynamic muscle contraction at comparable workloads. J.Appl. Physiol., v. 104, p. 439-445, 2008.

Efe, Esra Mercanooglu, et al. "Comparación del esmolol en bolos e infusión continua en la respuesta hemodinámica a la laringoscopia, intubación orotraqueal y esternotomía en cirugía de revascularización coronaria." J. Anesth. Braz. Brazilian Journal of Anesthesiology (Edicion en Espanol) v.64.p.247-252, 2014.

Fadel, P. J.; Ogoh, S.; Keller, D. M.; Raven, P. B. Recent insights into carotid baroreflex function in humans using the variable pressure neck chamber. Exp Physiol. v.88, n.6, p. 671-680, 2003. 
Fadel, P.J.; Stromstad, M.; Wray, D.W.; Smith, S.A.; Raven, P. B.; Secher, N. H. New insights into differential baroreflex control of heart rate in humans. Am J Physiol Heart Circ Physiol., v. 284, n. 2, p. H735-H743, 2003.

Fadel, P.J.; Wang, Z.; Tuncel, M.; Watanabe, H.; Abbas, A.; Arbique, D.; et al. Reflex sympathetic activation during static exercise is severely impaired in patients with myophosphorylase deficiency. J Physiol. v. 548, n.3, p. 983-93, 2004.

Figueroa, A.; Gil, R.; Sanchez-Gonzalez, M. A. Whole-body vibration attenuates the increase in leg arterial stiffness and aortic systolic blood pressure during post-exercise muscle ischemia. Eur. J. appl. Physiol., v. 111, p. 1261-1268, 2011.

Fisher, J.P.; Bell, M.P.; White, M. J. Cardiovascular responses to human calf muscle stretch during varying levels of muscle metaboreflex activation. Exp Physiol.v. 90, n.5, p.773-82, 2005. Fisher, J.P.; Bell, M.P.; White, M.J. Cardiovascular responses to human calf muscle stretch during varying levels of muscle metaboreflex activation. Exp Physiol. v. 90, n.5, p. 773-781, 2005.

Fisher, J. P.; Adlan, A. M.; Shantsila, A.; Secher, J. F.; Sorensen, H.; Secher, N. H. Muscle metaboreflex and autonomic regulation if heart rate in humans. J. Physiol.v. 591, n. 15, p. 37773788, 2013.

Fisher, J. P.; Fernandes, I. A.; Barbosa, T. C.; Prodel, E.; Coote, J. H.; Nobrega, A. C. L.; Vianna, L. C. Diving and exercise: The interaction of trigeminal receptors and muscle metaboreceptor on muscle sympathetic nerve activity in humans. Am J. Physiol. Heart Circ. Physiol, v.308, p.h367-H375, 2015. 
Fisher, J. P.; Sifert, T.; Hartwich, D.; Young, C. N.; Secher, N. H.; Fadel, P. J. Autonomic control of heart rate by metabolically sensitive skeletal muscle afferents in humans. J. Physiol., v. 588, n. 7; p. 1117-1127, 2010.

Fisher, J. P.; Young, C. N.; Fadel, P. J. Effect of muscle metaboreflex activation on carotidcardiac baroreflex fuction in humans. Am J. Physiol Heart Circ Physiol., v.294, p. H2296-H2304, 2008.

Gallagher, K.M.; Fadel, P.J.; Stromstad, M.; Ide, K.; Smith, S.A.; Querry, R. G.; et al. Effects of exercise pressor reflex activation on carotid baroreflex function during exercise in humans. $J$ Physiol. v. 533, n. 3, p.871-880, 2001.

Greaney, J. L. Matthews, E. L.; Boggs, M. E,; Edwards, D. G.; Duncan, R. L.; Farquhar, W. B. Exaggerated exercise pressor reflex in adults with moderately elevated systolic blood pressure: role of purinergicc receptors. Am J. Physiol. heart circ. Physiol., v. 306, p. H132-H141, 2014.

Gujic, m.; Laude, D.; Houssiere, A.; Beloka, S.; Argacha, J. F.; Adamopoulos, D.; Xhaet, O.; Elghozi, J. L.; Borne, P. V. Differential effects of metaboreceptor and chemoreceptor activation on sympathetic and cardiac baroreflex control following exercise in hypoxia in human. J. Physiol, v.585, n.1, p.165-175, 2007.

Harttwich, D.; Dear, W. E.; Waterfall, L.; Fisher, J. P. Effect of muscle metaboreflex activation on spontaneous cardiac baroreflex sensitivity during exercise in humans. J. Physiol., v. 589, n. 24, p. 6157-6171, 2011.

Hayashi, N.; Someya, N. Muscle metaboreflex activation by static exercise dilates pupil in humans. Eur J Appl Physiol, V. 111, p. 1217-1221, 2011. 
Hjortskov, N.; Skotte, J.; hye-Knudsen, C.; Falletin, N. Sympathetic outflow enhances the stretch reflex response in the relaxed soleus muscle in humans. J. appl. Physiol., v. 98, p. 13661379, 2005.

Holwerda, S. W.; Restaino, R. M.; Manrique, C.; Lastra, G.; fisher, J. P.; Fadel, P. J. Augmented pressor and sympathetic responses to skeletal muscle metaboreflex activation in type 2 diabetes patients. Am J Physiol. Heart Cir Physiol, v. 310, p. H300-H309, 2016.

Houssiere, A.; Najem, B.; Cuylits, N.; Cuypers, S.; Naeije, R.; Borne, P. V. Hyperoxia enchances metaboreflex sensitivity during static exercise in humans. Am J. Physiol. heart circ Physiol, v.291, p. H210-H215, 2006.

Hughson, R. L.; Cuervo, L.A.; Patla, A. E.; Winter, D.A.; Xing, H. C.; Dietrich, B. H.; Swanson, G. D. Time domain analysis of oxygen uptake during pseudorandom binary sequence exercise tests. J Appl Physiol. v. 71, p.1620-1626, 1991.

Ichinose, M.; Delliaux, S.; Watanabe, K.; Fuji, N.; Nishiyasu, T. Evaluation of muscle metaboreflex fuction though graded reduction in forearm blood flow during rhythmic handgrip exercise in humans. Am j. Physiol. heart circ. Physiol., v. 301, p. H609-H616, 2011.

lellamo, F.; Hughson, R. L.; Castrucci, F.; Legramante, J. M.; Raimondi, G.; Peruzzi, G.; Tallarida, g. Evaluation of spontaneous baroreflex modulation of sinus node during isometric exercise in healthy humans. J. Physiol. heart circ. Physiol., v. 267, n.36, p. h994-H1001, 1994.

lellamo, F.; Massaro, M.; Raimondi, G.; Peruzzi, Legramante, J. M. Role of muscular factors in cardiorespiratory responses to static exercise: contribution of reflex mechanisms. J. app. Physiol., v. 86, n. 1, p. 174-180, 1985. 
Iellamo, F.; Rienzo, M.; Lucini, D.; Legramante, J. M.; Pizzinelli, P.; Castiglioni, P.; Pagani, F.; Parati, G. Muscle metaboreflex contribution to cardiovascular regulation during dynamic exercise in microgravity: insights from mission STS-107 of the space shuttle Columbia. J. Physiol., v. 572, n.3, p. 829-838, 2006.

Kamiya, A.; michikami, D.; Fu, Q. I.; Niimi, Y.; Iwase, S.; Mano, T.; Suzumura, A. Static handgrip exercise modifies arterial baroreflex control of vascular sympathetic outflow in humans. Am J. Physiol. regulatory integrative comp Physiol., v. 281, p. R1134- R1139, 2001.

Kaufman, M. P.; Hayes, S. G. The exercise pressor reflex. Clin Auton Res.v.12, n.6, p. 429439, 2002.

Kaufman, M. P. The exercise pressor reflex in animals. Exp Physiol. v.97, n.1, p.51-58, 2012.

Keller-Ross, M.; Johnson, B. D.; Joyner, M. D.; Olson, T. P. Influence of the metaboreflex on arterial blood pressure in heart failure patients. Americ Heart journal, v. 163, n. 4, p.521-528, 2014.

Kim A, Deo SH, Vianna LC, Balanos GM, Hartwich D, Fisher JP, et al. Sex differences in carotid baroreflex control of arterial blood pressure in humans: relative contribution of cardiac output and total vascular conductance. Am J Physiol Heart Circ Physiol. v.301, n.6, p.H2454-H2465, 2011.

Kiviniemi, A. M.; Frances, M. F.; Rachinsky, M.; craen, R.; Petrella, R. J.; Huikuri, H. V.; Tulppo, M. P.; Shoemaker, J. K. Non-alpha-adrenergic effects on systemic vascular conductance during lower-body negative pressure, static exercise and muscle metaboreflex activation. Acta Physiol., v.206, n. 1, p. 51-61, 2012. 
Kiviniemi, A. M.; Frances, M. F.; Tiinanen, S.; Craen, R.; Rachinsky, M.; Petrella, R.; Seppanen, T.; Huikuri, H. V.; Tulppo, M. P.; Shoemaker, J. K. a-adrenergic effects on low-frequency oscillations in blood pressure an R-R intervals during sympathetic activation. Exp Physiol, v.98, n.8, p. 718-735, 2011.

Koba, S.; Xing, J.; Sinoway, LI.; Li, J. Sympathetic nerve responses to muscle contraction and stretch in ischemic heart failure. Am J Physiol Heart Circ Physiol. v. 294, n.1, p.H311-H321, 2008.

Kondo, N.; Yanagimoto, S.; Nishiyasu, T.; Crandall, C. G. Effects of muscle metaboreceptor stimulation on cutaneous blood flow glabrous and nonglabrous slin in midly heated humans. J. appl. Physiol. v. 94, p. 1829-1835, 2003.

Krogh, A.; Lindhard, J. The regulation of respiration and circulation during the initial stages of muscular work. J Physiol.v.47, p.112-136, 1913.

Kuipers, N. T.; Sauder, C. L.; Ray, C. A. influence of static magnetic fields on pain perception and sympathetic nerve activity in humans. J. appl. Physiol., v.102, p.1410-1415, 2007.

Lykidis, C. K.; Kumar, P.; Vianna, L. C.; White, M. J.; Balanos, G. M. A respiratory response to activation of the muscle metaboreflex during concurrent hypercapnia in man. Exp. Physiol., v.95, n.1, p. 194-201, 2010.

MacDonald, M. J.; Shoemaker, J.K.; Tschakovsky, M.E.; Hughson, R. L. Alveolar oxygen uptake and femoral artery blood flow dynamics in upright and supine leg exercise in humans. $J$ Appl Physiol. v.85, p. 1622-1628, 1998. 
Marongiu, E.; Piepoli,, M.; Milla, R.; Angius, L.; Pinna, M.; Bassareo, P.; Roberto, S.; Tocco, F.; Concu, A.; Crisafulli. Effects of acute vasodilation on the hemodynamic response to muscle metaboreflex., v. 305, p.H1387-H1396, 2013.

McGowan, C. L.; notaries, C. F.; McReynolds, A.; Morris, B. L.; Kimmerly, D. S.; Picton, P. E.; Floras, J. S. Effect of Angiotensin AT1 receptor blockade on sympathetic response to handgrip in healthy men. American; j. of hypertension, v. 24, n.5, p.538-543, 2011.

McNulty, C. L.; Moody, W. E.; Wagenmakes, A. J. M.; Fisher, J. P. Effect of muscle metaboreflex activation on central hemodynamic and cardiac fuction in humans. App. Physiol. nut. Metab. v.39, p.861- 870, 2014.

Mitchell, J. H.; Kaufman, M.P.; Iwamoto, G. A. The exercise pressor reflex: its cardiovascular effects, afferent mechanisms, and central pathways. Annu Rev Physiol; v.45, p.229-242, 1983.

Momen, A.; Cui, J.; McQuillan, P.; Sinoway, L. I. Local prostaglandin blockade attenuates muscle mechanoreflex-mediated renal vasoconstriction during muscle stretch in humans.

Morelli, A.; Ertmer, C.; Westphal, M.; et al. Effect of heart rate control with esmolol on hemodynamic and clinical outcomes in patients with septic shock: a randomized clinical trial. The Journal of the American Medical Association.v. 310, n.16, p. 1683-1691, 2013.

Murphy, M. N.; Ichiyama, R. M.; Iwamoto, G.A.; Mitchell, J. H.; Smith, S. A. Exercise pressor reflex function following acute hemi-section of the spinal cord in cats. Front Physiol. v.4, n.3, 2013. 
Negrao, C. E.; Trombetta, I. C.; Batalha, L. T.; Ribeiro, M. M.; Rondon, M;U.; Tinucci, T.; et al. Muscle metaboreflex control is diminished in normotensive obese women. Am J Physiol Heart Circ Physiol.v. 281, n. 2, p.H469-H475, 2001.

Nishiyasu, T.; Tan, N.; Morimoto, K.; Sone, R.; Murakami, N. Cardiovascular and humoral response to sustained muscle metaboreflex activation in humans. J. appl. Physiol. v.84, n.1, 1998, p.116-122,1985.

Notarius, C. F.; Atchison, D. J.; Floras, J.S. Impact of heart failure and exercise capacity on sympathetic response to handgrip exercise. Am J Physiol Heart Circ Physiol v. 280, p. H969H976, 2001.

Ogoh, S.; Fisher, J. P.; Youn, C. N.; Raver, P. B.; Fadel, P. J. Transfer Fuction Characteristics of the neural and peripheral arterial baroreflex ares at rest during postexercise muscle ischemia in humans. Am J. Physiol. heart circ. Physiol., v.296, p. H1416- H1424m 2009.

Padilla, J.; Young, C. N.; Simmons, G. H.; Den, S. H.; Newcomer, S, C.; Sullivan, J. P.; Laughlin, M. H.; Fadel, P. J. Increased muscle sympathetic nerve activity nerve acutely alters conduit artery shear rate patterns. Am j. Physiol. heart Cir. Physiol., v. 208, p. H1128-H1135, 2009.

Park, J.; Campese, V. M.; Middlekauff, H. R. Exercise pressor reflex in humans with end-stage renal disease. Am j. Physiol. regul. Integr. Com. Physiol., v.295, p.R1188-R1194, 2008.

Polito, M. D.; Nobrega, A. C. L.; Farinatti, P. Blood pressure and forearm blood flow after multiple sets of a resistive exercise for the lower limbs. Blood pressure monitoring, v. 16, n.4, p.180-185, 2011. 
Pott, F.; Ray, C. A.; Olesen, H. L.; Ide, K.; Secher, N. H. Middle cerebral artery blood velocity, arterial diameter and muscle sympathetic nerve activity during post-exercise muscle ischaemia. Acta Physiol. Scand., v.160, p. 43-47, 1997.

Prodel, E.; balanos, G. M.; Braz, I. D.; Nobrega, A. C. L.; Vianna, L. C.; Fisher, J. P. Muscle metaboreflex and cerebral flow regulation in human: implications for exercise with blood flow restriction. Am j. Physiol. heart circ. Physiol., v.310, n. 9, p. H1201- H1209, 2016.

Ray, C. A.; Wilson, T. E. Comparison of skin sympathetic nerve responses to isometric arm and leg exercise. J. appl Physiol., v.97, p.160-164, 2003.

Rondon, M.U.; Laterza, M.C.; de Matos, L.D.; Trombetta, I. C.; Braga, A. M.; Roveda, F. et al. Abnormal muscle metaboreflex control of sympathetic activity in never-treated hypertensive subjects. Am J Hypertens.v. 19, n.9, p. 951-957, 2006.

Sadamoto, T.; Kusano, M.; Yamagiwa, T. Attenuated cardiovascular adjustment to sustained static exercise after carbohydrate loading. J. of the autonomic nervous system. v. 80, n. 3, p. 175-182, 2000.

Saito, M. Differences in muscle sympathetic nerve response to isometric exercise in different muscle groups. Eur J. appl. Physiol. v.70, p.26-35, 1995.

Sander, M.; Macefield, V. G.; Henderson, L. Cortical and brain stem changes in neural activity during static handgrip and postexercise ischemia in humans. J. appl, Physiol., v.108, p.16911700, 2010.

Shoemaker, J. K.; Herr, M. D.; Sinoway, L. I.; dissociation of muscle sympathetic nerve activity and leg vascular resistance in humans. Am j. Physiol. heart circ. Physiol. v. 279, p. H1219H1219, 2000. 
Smith, S.A; Mitchell J. H.; Garry, M.G. The mammalian exercise pressor reflex in health and disease. Exp Physiol. v. 91, n. 1, p. 89-102, 2006.

Smith, S.A.; Mitchell, J.H.; Li, J. Independent modification of baroreceptor and exercise pressor reflex function by nitric oxide in nucleus tractus solitarius. Am J Physiol Heart Circ Physiol. v.288, n.5, p.H2068-H2076,2005.

Smith, S.A.; Williams, M.A.; Leal, A.K.; Mitchell, J.H.; Garry, M.G. Exercise pressor reflex function is altered in spontaneously hypertensive rats. J Physiol.v.577, n. 3, p. 1009-1020, 2006.

Spaak, J.; Sundlad, P.; Linnarsson, D. Human carotid baroreflex during isometric lower arm contraction and ischemia. Am. J. Physiol., v. 275, n.3, H940-H945, 2008.

Tokizawa, K.; Mizuno, M.; Hayashi, N.; Muraoka, I. Cardiovascular responses to static extension and flexion of arms and legs. Eur j. appl. Physiol. v. 97, p.249-252, 2006.

Tsuchimochi, H.; Hayes, S.G.; McCord, J.L.; Kaufman, M. P. Both central command and exercise pressor reflex activate cardiac sympathetic nerve activity in decerebrate cats. Journal Physiology Heart circulation. v. 296, n. 4, p. H1157-H1163.

Turley, K. R.; The chemoreflex: adult versus child comparison. Medicine e science in sports e exercise, 2005

Vianna, L. C.; Araujo, C.G.; Fisher, J. P. Influence of central command and muscle afferent activation on anterior cerebral artery blood velocity responses to calf exercise in humans. J Appl Physiol. v.107, n.4, p.1113-1120. 2009. 
Vianna, L. C.; Oliveira, R. B.; Ramos, P.S; Ricardo, D.R.; Araujo, C.G. Effect of muscle mass on muscle mechanoreflex-mediated heart rate increase at the onset of dynamic exercise. Eur J Appl Physiol. v.108, n.3, p.429-434, 2010.

Vieira, P. J. C.; Ribeiro, J. P.; Cipriano Jr, G.; Umpierre, D.; Cahalim, L. P.; Moraes, R. S.; Chiappa, G. R. Effect of transcutaneous eletrical nerve stimulation on muscle metaboreflex in healthy Young and older subjects. Eur. J. Appl. Physiol., v.112, p. 1327-1334, 2012.

Williamson, J.W; Fadel, P.J.; Mitchell, J.H. New insights into central cardiovascular control during exercise in humans: a central command update. Exp Physiol. v.101, n.1, p. 51-8, 2006.

Williamson, J. W.; Nobrega, A.C.; Winchester, P. K.; Zim, S.; Mitchell, J. H. Instantaneous heart rate increase with dynamic exercise: central command and muscle-heart reflex contributions. $J$ Appl Physiol. v.78, n.4, p.1273-1279, 1995.

Williamson, J. W.; Mccoll, R.; Mathews, D. Evidence for central command activation of the human insular cortex during exercise. J. appl. Physiol. v.94, p. 1726-1734, 2003. 


\section{ANEXO- TERMO DE CONSENTIMENTO LIVRE E ESCLARECIDO}

Convidamos o(a) Senhor(a) a participar do projeto de pesquisa "Interação entre reflexos cardiopulmonar e pressor do exercício: impacto no controle fisiológico da pressão arterial em humanos", sob a responsabilidade do pesquisador Prof. Dr. Lauro Casqueiro Vianna. O projeto envolve exercício isométrico de preensão manual e exercício dinâmico em uma bicicleta ergométrica em postura ereta e deitada, para melhor investigação dos mecanismos de controle da pressão arterial.

O objetivo desta pesquisa é compreender os mecanismos fisiológicos que contribuem para a regulação da pressão arterial em adultos que possuem a pressão arterial de acordo com os padrões normais estabelecidos pelas entidades internacionais responsáveis.

O(a) senhor(a) receberá todos os esclarecimentos necessários antes e no decorrer da pesquisa e lhe asseguramos que seu nome não aparecerá sendo mantido o mais rigoroso sigilo pela omissão total de quaisquer informações que permitam identificá-lo(a)

A sua participação se dará por meio de algumas avaliações no NeuroVASQ Laboratório de Fisiologia Integrativa localizado na Faculdade de Educação Física da Universidade de Brasília, para saber seu número de batimentos cardíacos em um minuto, sua pressão arterial no braço e no dedo, fluxo sanguíneo na perna, a força máxima da sua mão assim como sua familiarização com os procedimentos do estudo. Posteriormente você será encaminhado ao Instituto de Cardiologia do Distrito Federal (DF), onde daremos início ao protocolo de exercício isométrico, como informado previamente será infundida em seu braço um cateter para aplicação da droga Esmolol (0,5 por kg do seu peso com acréscimos para realizarmos uma diminuição do seu número de batimentos cardíacos por minuto), após esse procedimento você deverá apertar um objeto com uma de suas mãos por 2 minutos, e imediatamente após os 2 min. faremos a oclusão circulatória (obstrução temporária de vias sanguíneas), inflando uma cinta pneumática na parte proximal do braço em exercício durante 5 minutos. Caso seja sorteado para o protocolo de exercício dinâmico, você deverá realizar 7 minutos de exercício em uma bicicleta ergométrica normal, na posição sentado e deitado. Após 
4 minutos desse exercício, faremos a oclusão, inflando uma cinta pneumática na metade da coxa durante 5 minutos.

Os riscos decorrentes de sua participação na pesquisa estão relacionados ao cansaço muscular, diminuição abrupta do ritmo cardíaco e aumento da respiração. Tais riscos são diminuídos pela inteira atenção do pesquisador e da equipe médica composta por cardiologistas e anestesiologistas do Instituto de Cardiologia do Distrito Federal, para a execução e acompanhamento dos participantes durante todo esse estudo. $O$ voluntário também pode apresentar leve desconforto devido aos procedimentos, contudo, a equipe ligada a pesquisa estará próxima visando sua segurança. Se você aceitar participar, estará contribuindo para o benefício esperado com este trabalho, que é a descoberta de como a interação entre os reflexos cardiopulmonar e reflexo pressor do exercício atuam na regulação da pressão arterial com indivíduo na postura ereta e supino. Uma vez entendido este mecanismo, ele poderá servir como alvo para o desenvolvimento de futuros estudos com populações acometidas por diferentes patologias.

$\mathrm{O}$ (a) Senhor(a) pode se recusar a responder (ou participar de qualquer procedimento) qualquer questão que lhe traga constrangimento, podendo desistir de participar da pesquisa em qualquer momento sem nenhum prejuízo para o(a) senhor(a). Sua participação é voluntária, isto é, não há pagamento por sua colaboração.

Todas as despesas que você tiver relacionadas diretamente ao projeto de pesquisa (passagem para o local da pesquisa, alimentação no local da pesquisa ou exames para realização da pesquisa) serão cobertas pelo pesquisador responsável. Seguindo as normas do CNS 466/2012, item IV. 3, subitem g.

Caso haja algum dano direto ou indireto resultante dos procedimentos de pesquisa, você poderá ser indenizado, obedecendo-se as disposições legais vigentes no Brasil.

Os resultados da pesquisa serão divulgados na Faculdade de Educação Física da Universidade de Brasília, podendo ser publicados posteriormente. Os dados e materiais utilizados na pesquisa ficarão sob a guarda do pesquisador por um período de no mínimo cinco anos, após isso serão destruídos ou mantidos na instituição. 
Se o(a) Senhor(a) tiver qualquer dúvida em relação à pesquisa, por favor telefone para: Lauro Casqueiro Vianna, na Faculdade de Educação Física da Universidade de Brasília, no telefone 61-3107-2532 ou 61-9951-1105, no horário entre 08:00 h e 18:00 h.

Este projeto foi Aprovado pelo Comitê de Ética em Pesquisa da Faculdade de Ciências da Saúde (CEP/FS) da Universidade de Brasília. O CEP é composto por profissionais de diferentes áreas cuja função é defender os interesses dos participantes da pesquisa em sua integridade e dignidade e contribuir no desenvolvimento da pesquisa dentro de padrões éticos. As dúvidas com relação à assinatura do TCLE ou os direitos do participante da pesquisa podem ser obtidos através do telefone: (61) 3107-1947, e-mail cepfs@unb.br ou cepfsunb@gmail.com, ou pelo endereço do CEP: Faculdade de Ciências da Saúde- Campus Darcy Ribeiro, Asa Norte, CEP. 70.910-900, Brasília-DF; horário de atendimento de 10hs às $12 \mathrm{hs}$ e de $14 \mathrm{hs}$ às $17 \mathrm{hs}$, de segunda a sexta-feira.

Este documento foi elaborado em duas vias, uma ficará com o pesquisador responsável e a outra com o Senhor(a).

Nome / assinatura

Pesquisador Responsável

Brasília, de de 